\title{
Research Paper \\ Effectiveness of Cognitive Rehabilitation Program on Attention Dimensions and Reading Efficacy in Students with Dyslexia
}

\section{Neda Safari ${ }^{1}$, Fereshteh Baezzat ${ }^{* 2}$, Majid Ghaffari ${ }^{3}$}

1. M.A. in Educational Psychology, Faculty of Humanities and Social Studies, University of Mazandaran, Babolsar, Iran 2. Associate Professor, Department of Psychology, Faculty of Humanities and Social Studies, University of Mazandaran, Babolsar, Iran

3. Assistant Professor, Department of Psychology, Faculty of Humanities and Social Studies, University of Mazandaran, Babolsar, Iran

Citation: Safari N, Baezzat F, Ghaffari M. Effectiveness of cognitive rehabilitation program on attention dimensions and reading efficacy in students with dyslexia. Quarterly Journal of Child Mental Health. 2020; 7(3): 167-181.

http://dx.doi.org/10.52547/jcmh.7.3.14

\section{A R T I C L E I N F O}

\section{Keywords:}

Attention,

dyslexia, cognitive rehabilitation, reading efficacy

Received: 30 Sep 2018

Accepted: 17 Feb 2019

Available: 2 Dec 2020

\section{A B S T R A C T}

Background and Purpose: Dyslexia is the most common learning disability. One of the most important factors associated with dyslexia is attention which can affect reading accuracy, speed and comprehension. Present study aimed to investigate the effectiveness of cognitive rehabilitation program and attention reinforcement on the dimensions of attention and reading efficacy in students with dyslexia.

Method: This research was a quasi-experimental study with control group pretest-posttest design. The study population included all the male primary school students of grade 3 in Kermanshah in the academic year 2016-2017. Among them, 30 students with dyslexia were selected by convenience method and then randomly assigned to either the experimental or control group (15 in each group). The experimental group received the cognitive rehabilitation program for 12 sessions of 45 minutes, while the control group underwent no intervention. Wechsler Intelligence Scale for Children- Fourth Edition), Reading Disorder Test, Stroop Test, Wisconsin Card Sorting Test, and Continuous Performance Test were used as the study tools and data were analyzed by repeated measures ANOVA.

Results: The findings of the study showed that cognitive rehabilitation program was effective on selective attention, shifting attention, and reading efficacy of students with dyslexia and the effect of this intervention was persistent after two-month follow up period, however there was no significant effect on sustained attention (Commitment error: $\mathrm{F}=1.52, \mathrm{p} \geq 0.05$; Negligence error: $\mathrm{F}=2.32, \mathrm{p} \geq$ 0.05; Reaction time: $\mathrm{F}=0.13, \mathrm{p} \geq 0 / 05)$.

Conclusion: Based on the results of this study, it can be concluded that by strengthening the dimensions of attention and increasing the accuracy and more accurate processing of letters and words read, the intervention method used in this study improves the reading efficacy of students with dyslexia.

\footnotetext{
* Corresponding author: Fereshteh Baezzat, Associate Professor, Department of Psychology, Faculty of Humanities and Social Studies, University of Mazandaran, Babolsar, Iran.

E-mail addresses: Baezzat12@gmail.com
} 


\section{اثربخشى برنامه توانبخشى شناختى توجه بر ابعاد توجه و كار آمدى خواندن دانش آموزان نارساخوان

\section{ندا صفرى'، فرشته باعزت"}

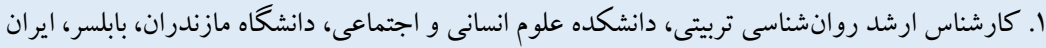

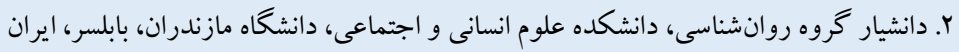

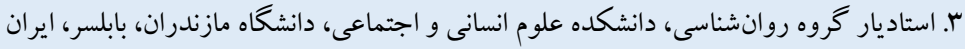

زمينه و هدف: نارساخوانى رايج ترين نوع اختلال يادگيرى خاص است. يكى از مهم ترين عو املى كه با نارساخوانى در ارتباط است، دامنه

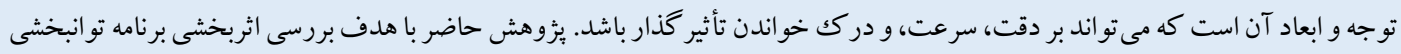
شناختى و تقويت توجه بر ابعاد توجه و كار آمدى خو اندن دانش آموزان نارساخوان انجام شدر.

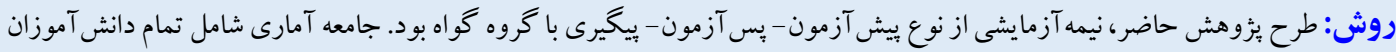

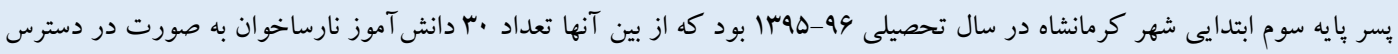

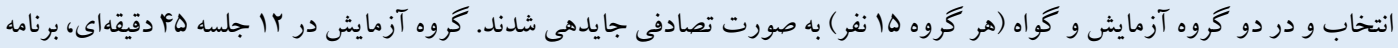

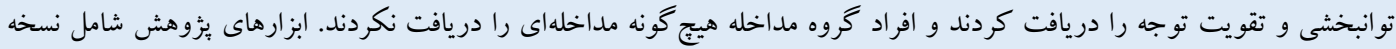

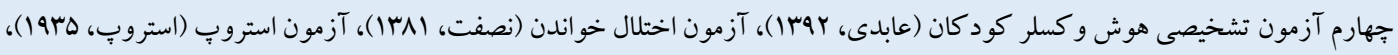

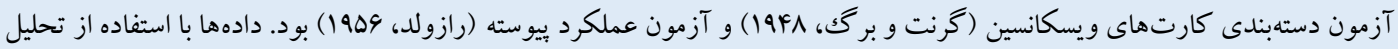

$$
\text { واريانس با تكرار اندازه گيرى تحليل شدند. }
$$

يافتهها: يافته هاى يُوهش نشان دان داد برنامه توانبخشى شناختى توجه، بر توجه انتخابى، توجه انتقالى، و كار آمدى خواندن داند دانش آموزان

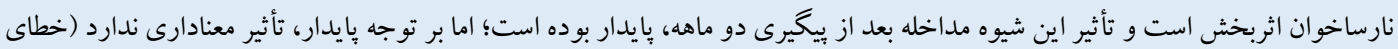

$$
\text { ارتكاب: r/ه }
$$

دريافت شده: نتيجه كيرى: بر اساس يافتهاى يُزوهش حاضر، مى توان نتيجه گرفت كه روش مداخله به كار گرفته شده در اين مطالعه با تقويت ابعاد

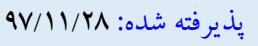
توجه و افزايش دقت و يردازش دقيق تر حروف و كلمات خوانده شده، باعث بهبود كار آمدى خواندن دانش آموزان نارساخوان شده است. 
نارسـايى اين عو امل با نارسـاخو انى نشــان داده شـــه اسـت (II و YI).

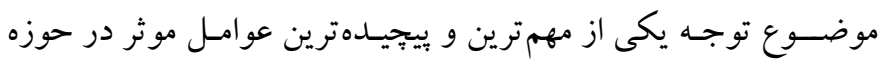

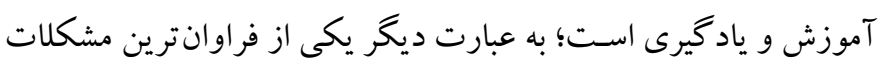

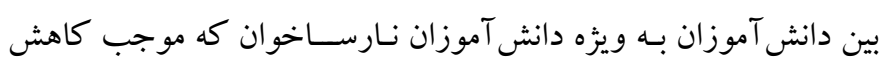

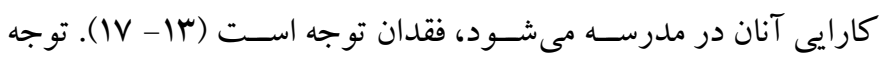

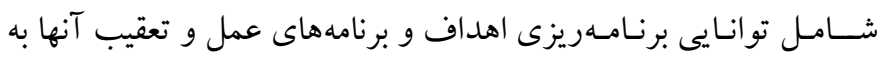

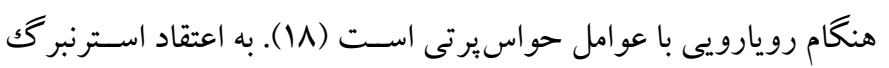

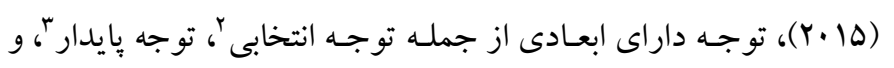

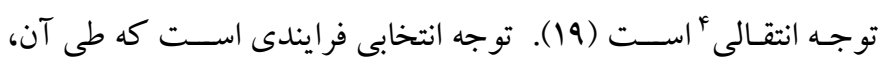

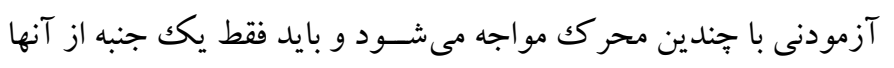

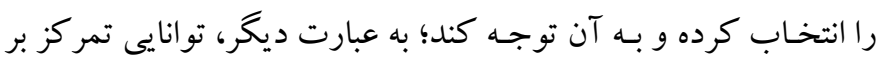

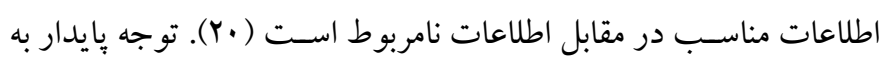

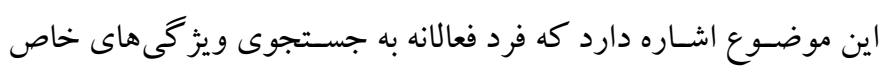
محر كك هـدف مى يردازد كـه مطمئن نيسـت در آن محيط وجود دارد دارد.

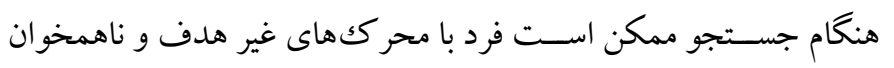

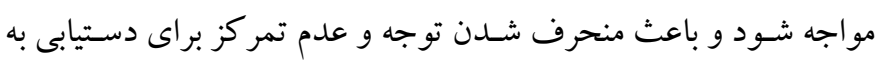

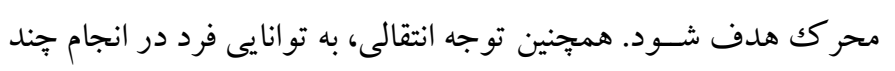
كار متفاوت در يكك زمان اشاره دارد (19).

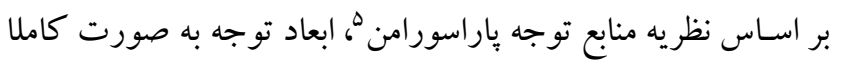

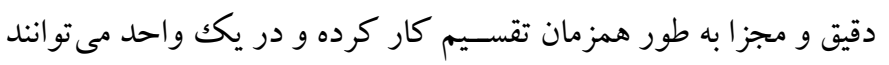

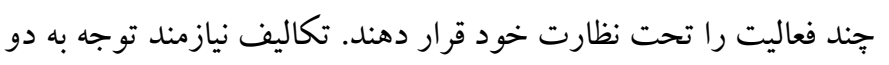

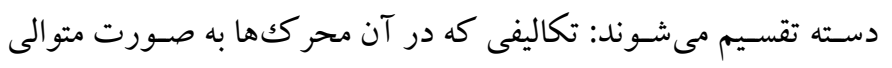

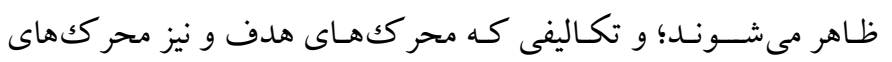

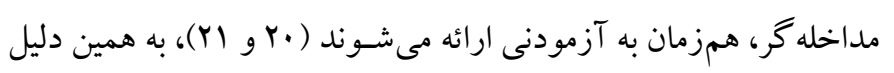

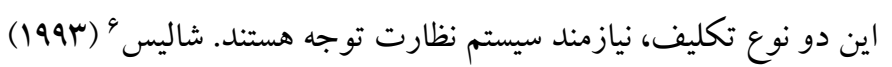

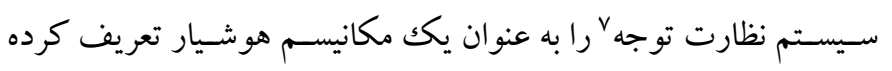

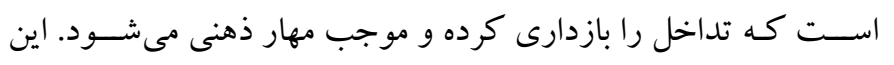

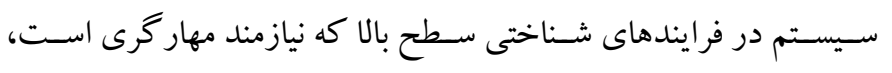

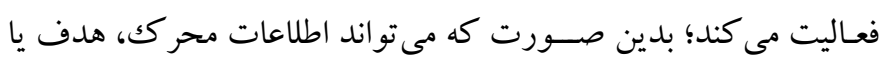

5. Parasuraman

6. Shallice

7. Supervisory attentional system

\section{مقلممه}

نارسـاخوانى ' اختلالى عصبشهناختى است كه بر تو انايى مغز در دريافت،

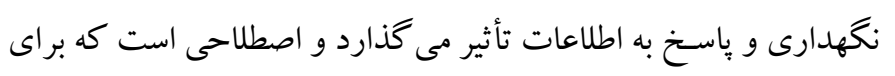

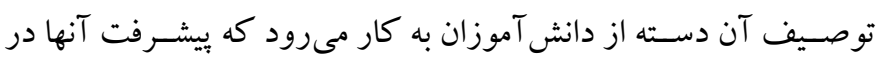

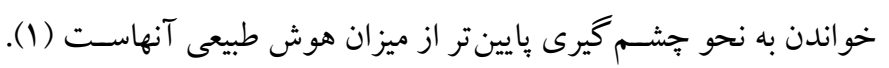

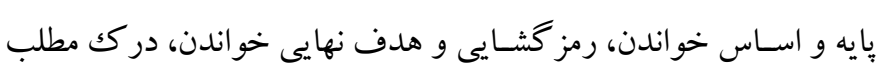

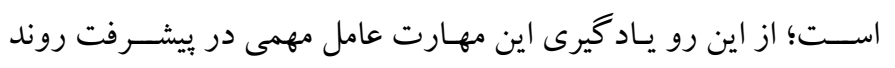

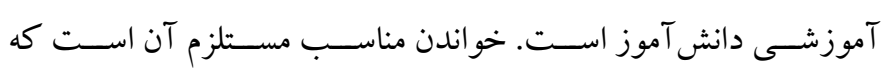

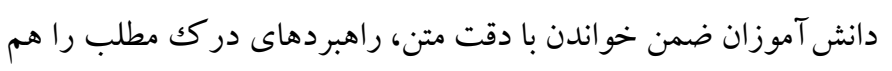

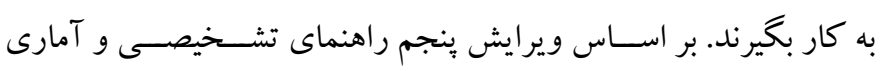

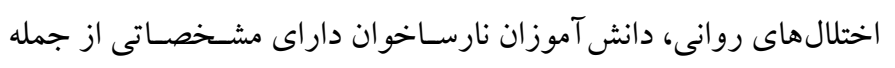

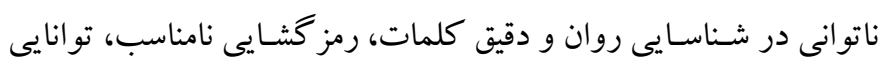
ضـعيف هجى كردن، و اشـكال در دركك معناى متن خواندن، هســتند.

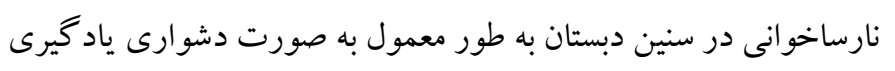

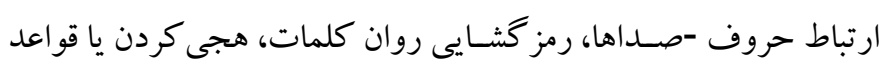

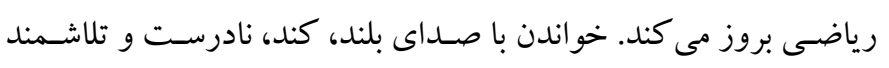

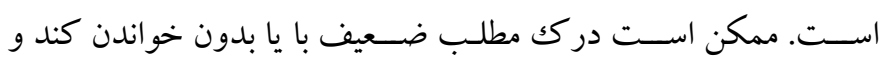

نادرست و تلاشمند همر اه باشد (Y). با وجود تمام مشـكلاتى كه دانش آموزان نارساخوان دارند، اما داراى بـ باى ظاهرى طبيعى و هوشبهرى متوسط يا بالاتر از متوسط هستند. شايد اولين

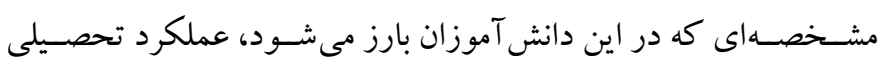

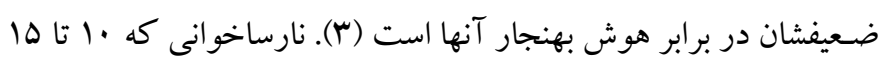

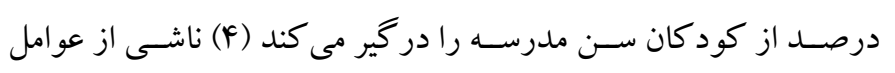

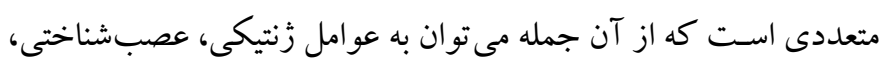

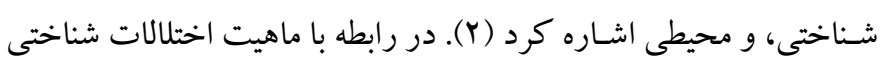

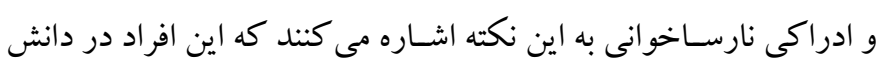

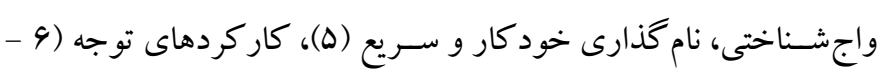

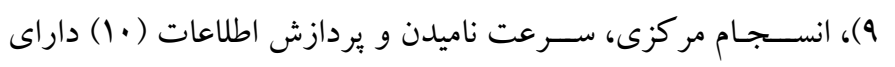

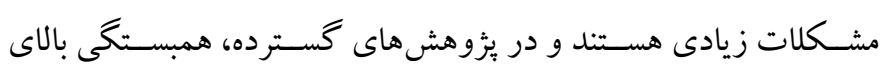

1. Dyslexia

2. Selective attention

3. Sustained attention

4. Shifting attention 
آموزشى و ارتباط آنها با تغييرات در فعاليتهاى مغزى مى شود. فارياس،

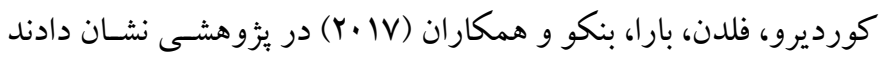

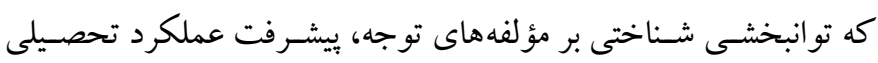

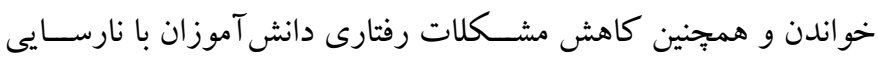

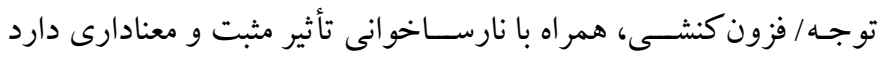

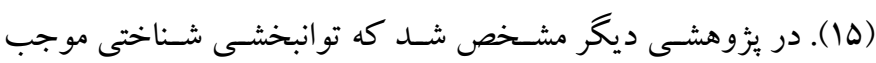
افزايش ســرعت يردازش و ذخيره حافظه كارى در دانش آموزان داراى

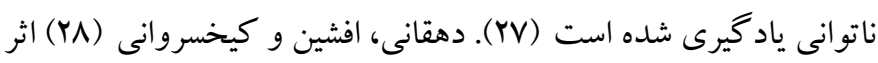
تو انبخشى شـناختى بر كنشهاى اجر ايى و عملكرد درسى دانش آموزان مبتلا به حسـاب نارسـايى را مورد بررسى قرار دادند. نتايج ئزوهش آنها

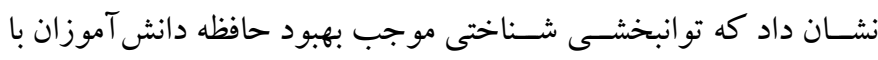
حسـاب نارسـايى و بهبود عملكرد تحصسيلى آنها شــده اسـت. همجينين رحمانى، ويرانى، حيدرى و داوودى (Y9) به بررسى تو انبخشى شناختى و

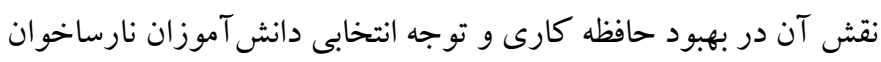

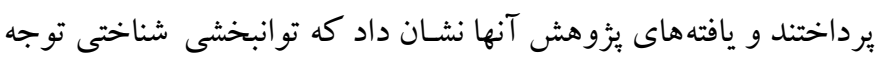

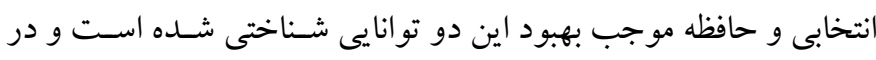

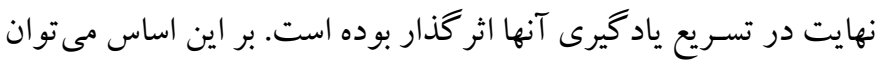

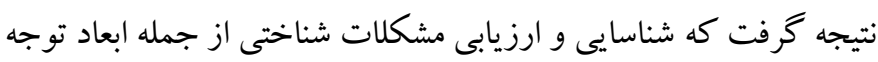

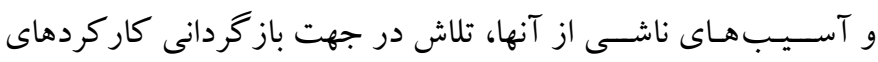

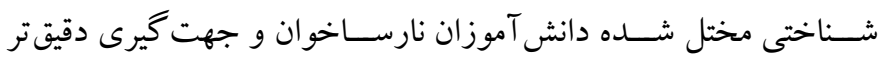
مـداخله، و برنامهريزى مناسـبـ در بازتوانى و بهـبود مشــكلات آنها

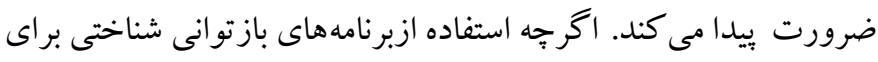

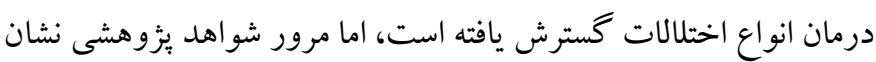

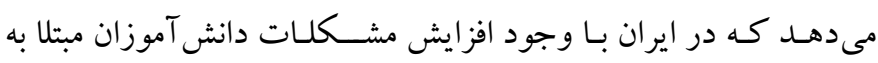

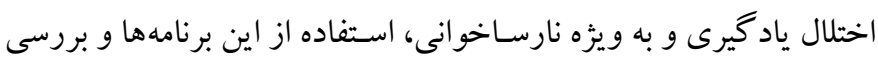

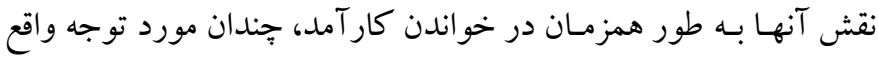

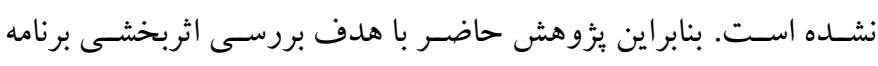

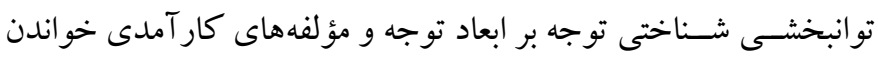
دانش آموزان نارساخو ان انجام شد.
محتو ا را بـه صــورت فعال و قابل دســترس در مواجهه با تداخل عوامل

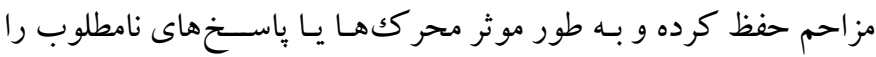

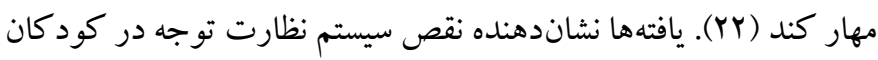

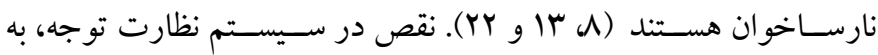

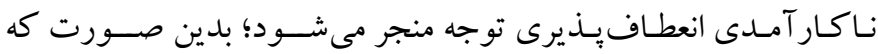

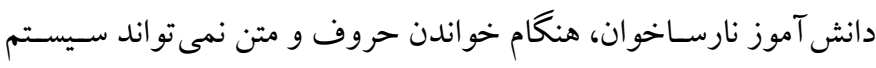

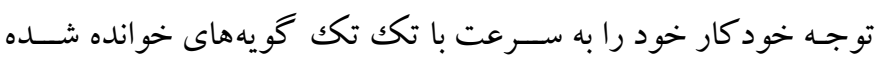

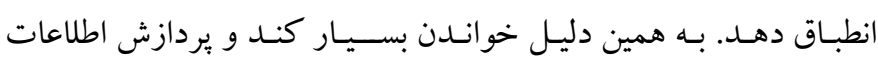

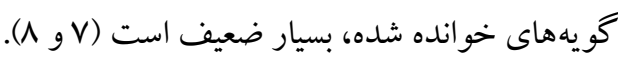

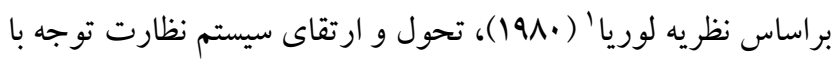

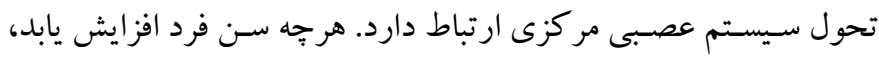

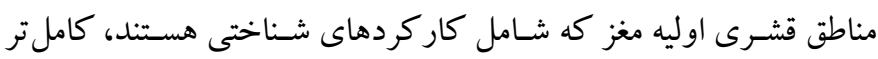

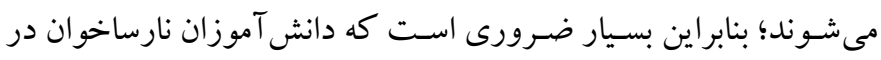

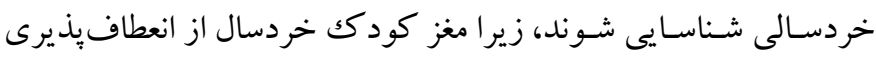
زيادى برخوردار اسـت و به صـورت بالقوه مى تو اند به مسـيريابى مجدد

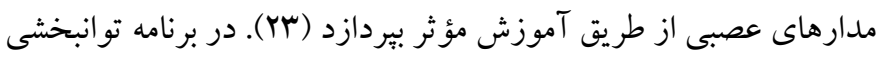

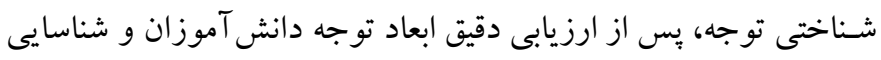

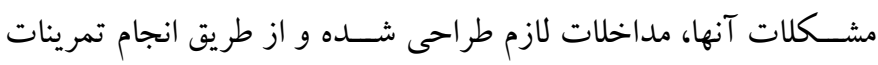

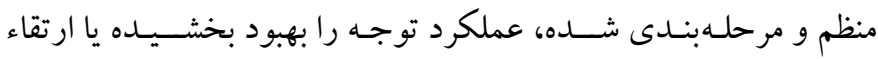

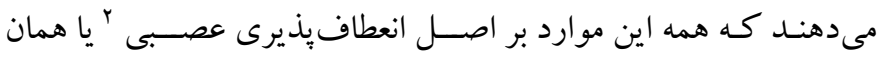

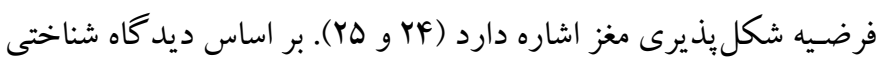
فرضيه شكل يذيرى مغز، هر كاه ميز ان تحريككهاى وارد شده به به مغز زياد

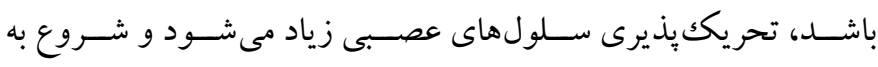

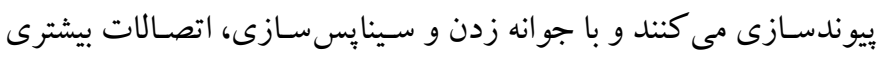

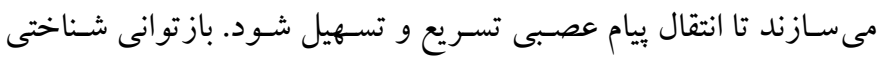

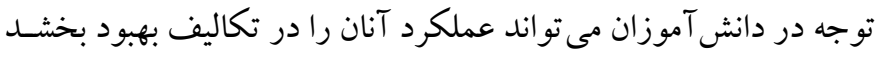

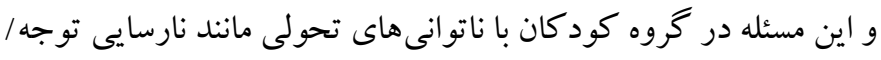

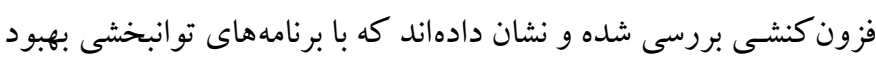
توجه، فعالسازى مغز در اين كود كان تغيير و بهبود مى يابد (Y4).

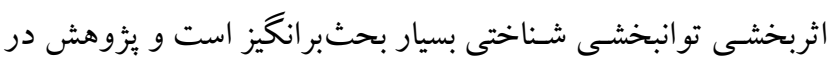

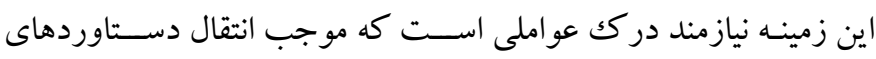

1. Loria 


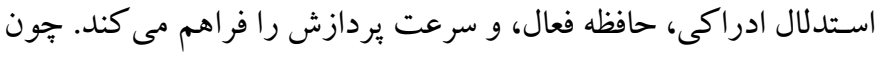

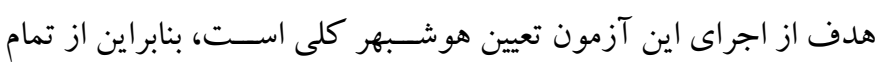

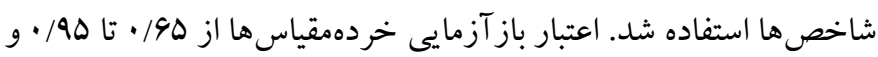

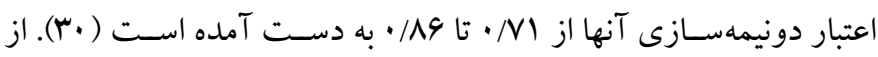
مقياس هوش ريون كه دفتر مشاوره و يزوهش آموزش و يرورش (سTVIT) براى كل كشور هنجاريابى كرده است به منظور بررسى روايى و محاسبه

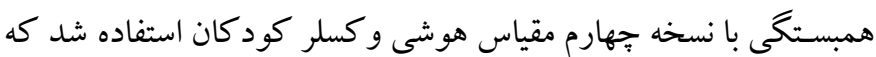

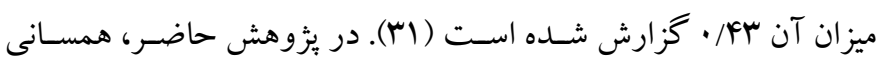

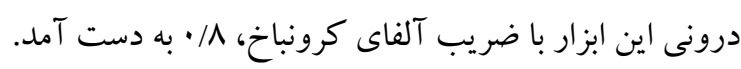

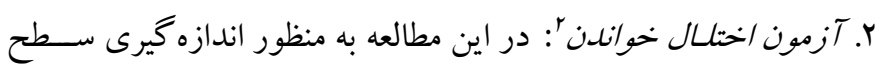
توانيى خو اندن و تشــخيص دانش آموزان نارسـاخو ان از آزمون اختلال خواندن نصفت (به نقل از بr) استيفاده شد. اين آزمون داراى سه مقورله

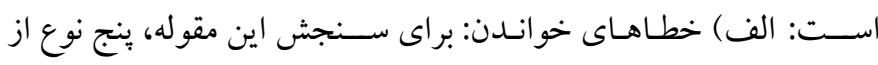

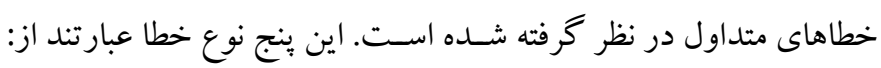

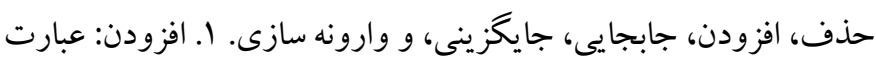

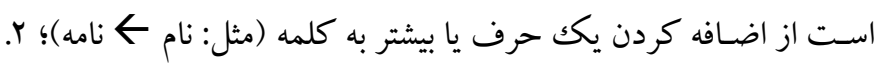
حذف: عبارت اسـت از كمشــدن يكك حرف يا بيشــتر در كلمه (مثال:

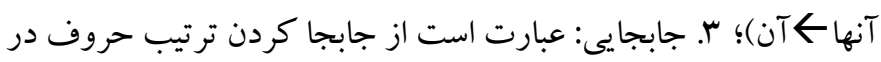

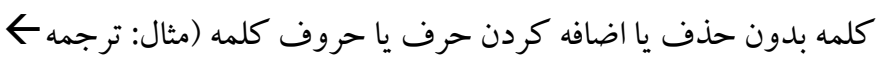

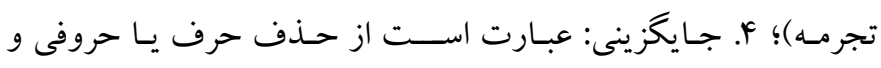
اضـافهـكردن حرف يـا حروف ديخرى بـه جـاى آن (در واقع خطساى

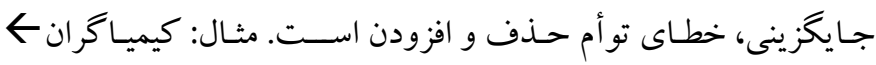

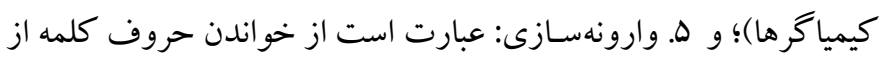

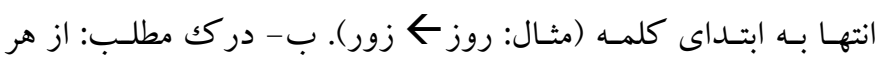

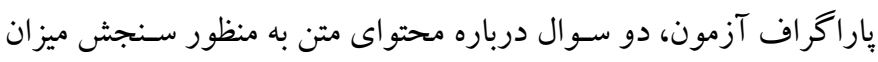

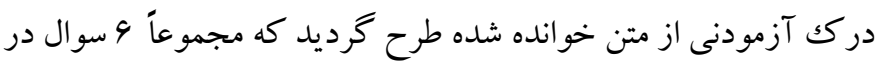

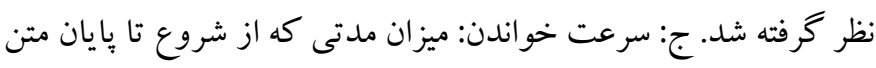

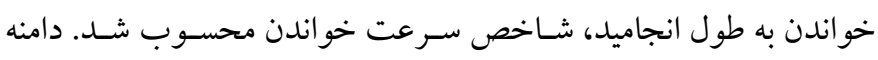

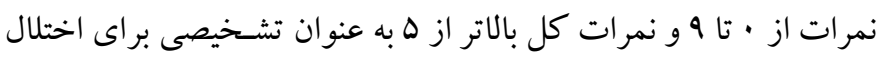

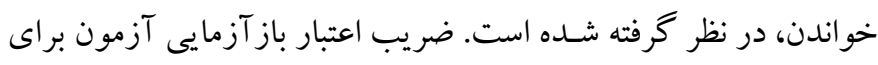
بايه سوم وه/ • به دست آمده است. به منظور محاسبه ضر ايب روايى، بين

2. The Reading Disorder Test
روش الف) طرح يُوهش و شر كت كنند ان : يُزوهش حاضر نيمه آزمايشى

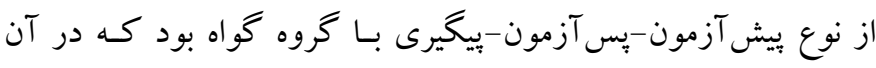

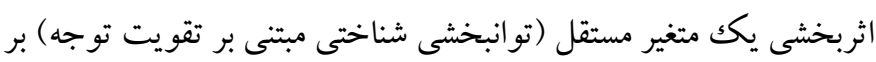

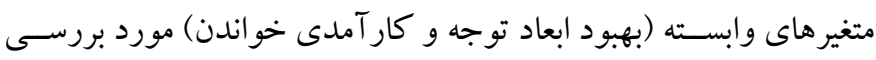

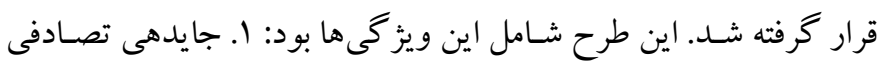

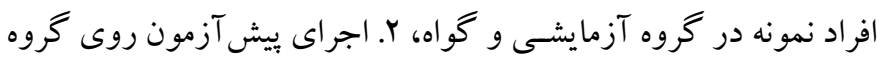

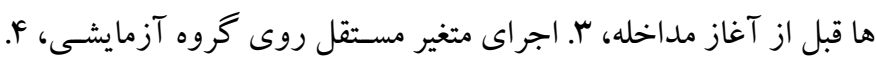

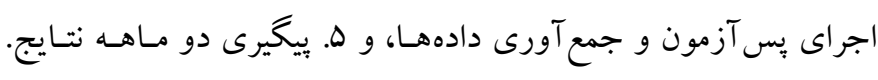
جامعه آمارى اين بُزوهش شامل تمام دانش آموزان بسر بِ يايه سوم ابتدايى مشغول به تحصيل در مدارس شهرستان كرمانشاه در سال تحصيلى $99-$

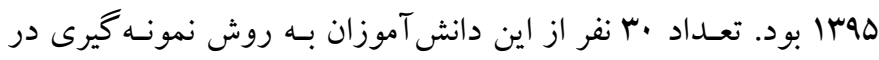

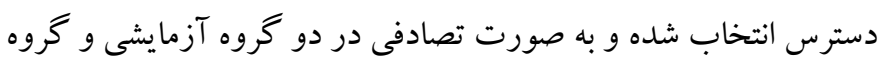

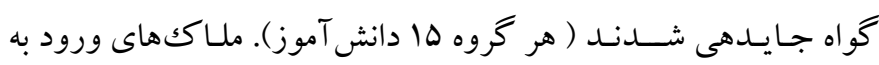

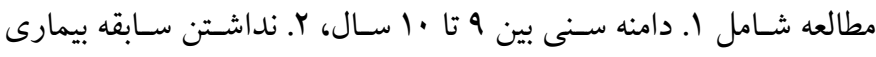

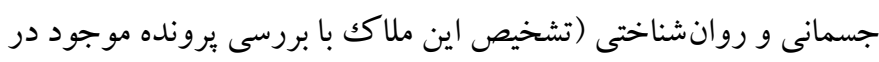

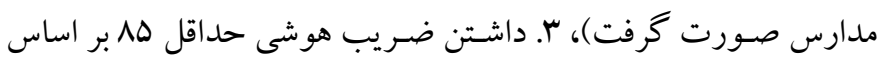

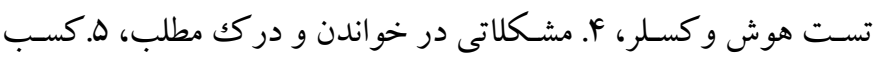

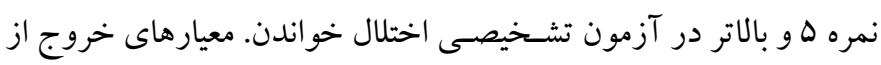
مطالعه شامل غيبت در دو جلسه آموزشى، داشتن آسيب شنوايى و بينايى، داشـتن اختلالات عصبى مزمن بزشكى مانند صرع (اين موارد نيز براساس

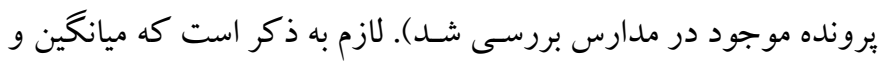

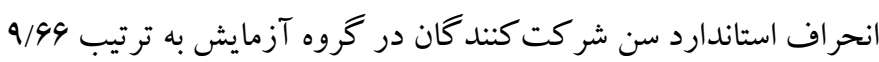

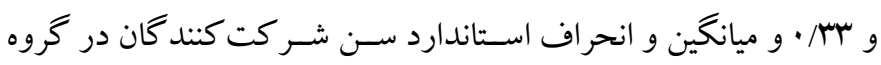

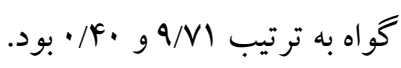

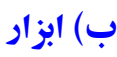
ا. نسخه جهارم مقياس هوشسى وكسلر كودكان ': به منظور اندازه گيرى

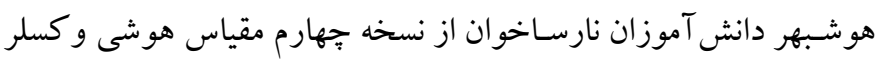

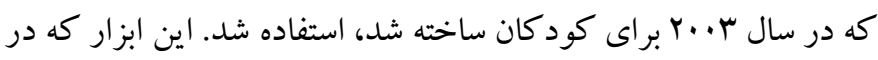

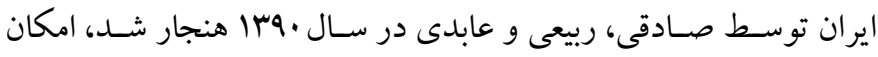

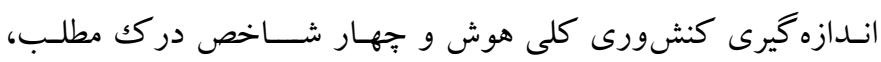


قرمز، سـبز، زرد و آبى وجود دارد. تعداد هريكك از شكل ها روى كارت

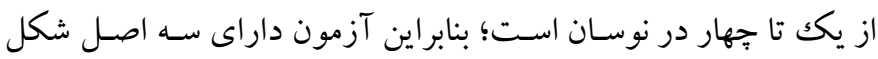

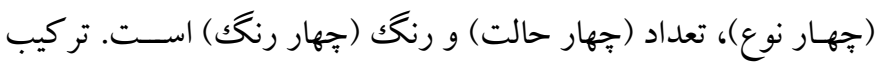

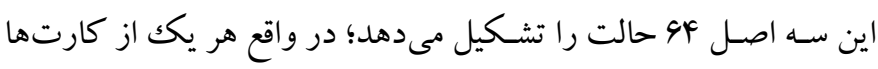
نمايانكر حالتى اسـت كه تكرار نمى شــود. در اين آزمون، آزمودنى بايد مفهوم يا قانونى راكه در مرحلهاى از آزمايش دريافته است، در دورههاى متوالى حفظ كند و وقتى قانون دسـتهبندى تغيير كرد، او نيز مفاهيم قبلى

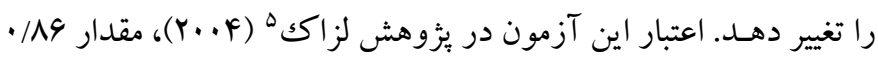

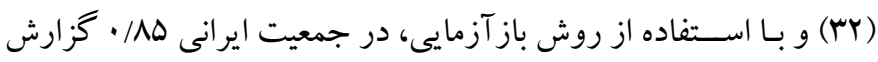

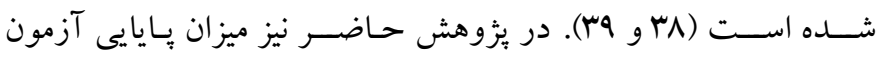

ويسكانسين با استفاده از ضريب آلفاى كرونباخ وع/ • به دست آمد.

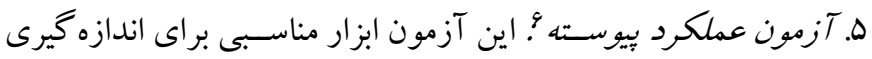

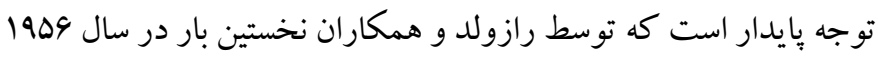

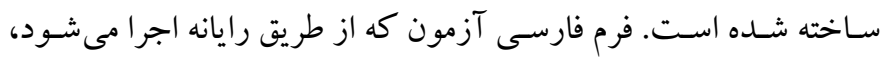

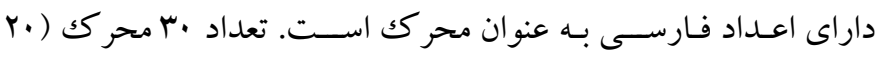
درصد) به عنوان محرك هدف در نظر گرفته شده است. فاصله بين ارائه

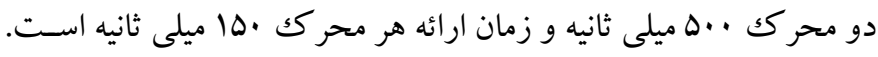
به آزمودنى گفته مىشـود كه يك سرى اعداد در صفحه مانيتور ظاهر و

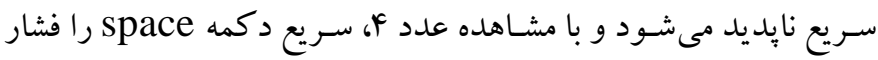
دهد ولى نسبت به ساير اعداد هيج واكنشى نشان ندهد. اعتبار اين آزمون

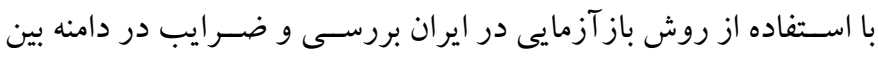

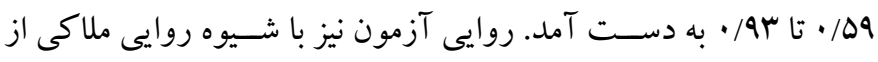

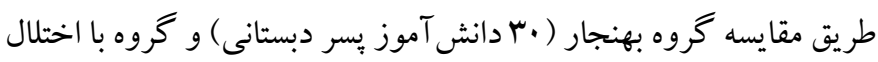
نارسايى توجه / فزون كنشى ( Tه دانش آموز يسر دبستانى) محاسبه شد.

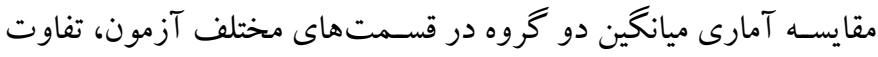

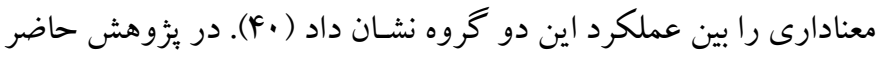

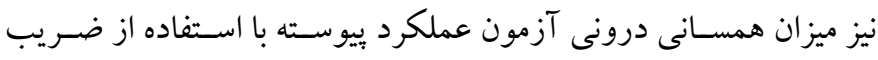

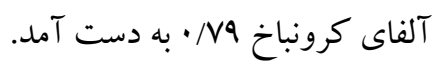

\section{Grant \& Berg}

5. Lezac

6. Continuous Performance Test
ملـاككهـاى فوق و توان كلى خواندن، ضــريب همبسـتخى بين نمرات خو اندن فارسى( كه نمره آزمودنى در ترم اول درس قر ائت فارسى ملاكك

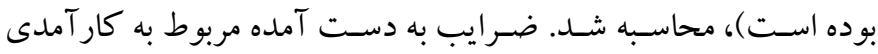

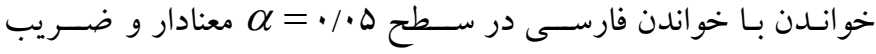

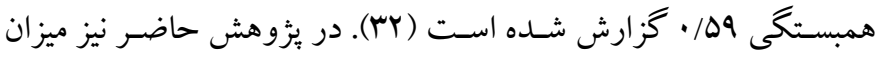

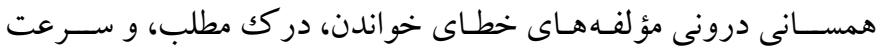

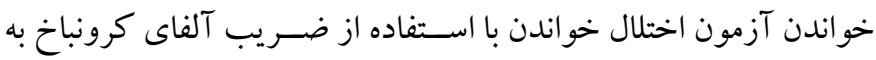

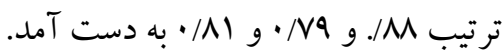

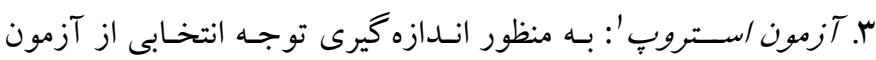
رايانهاى استروٍٍ استفاده شد. اين ابزار نخستين بار در سال هو9 اتوسط

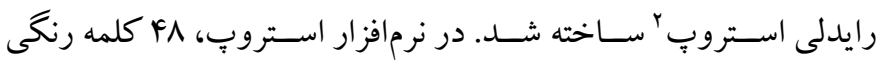
همخوان (رنگك كلمه با معناى كلمه يكسـان است؛ رنگگ قرمز، زرد، سبز

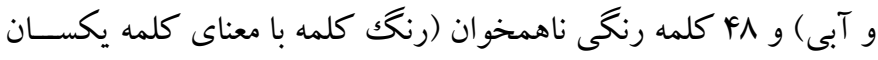

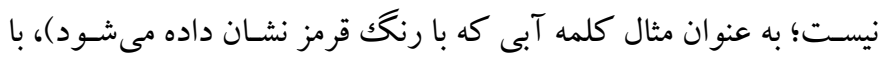

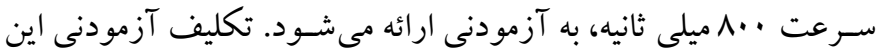
اسـت كه با استفاده از حروف مشخص شده در صفحه كليد كامييوتر، به محر كك ارائه شــده توجه كند و رنغك صـحيح را انتخاب كند. به منظور

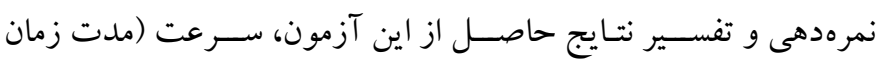

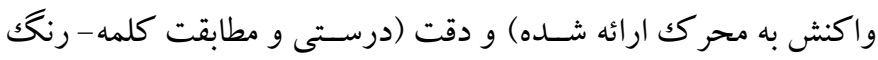
ظاهر شــده در كاميوتر ) به عنوان نمره كل توجه انتخابى در نظر كرفته

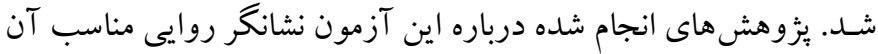
در ســنجش توجه انتخابى در كود كان و بزر گســالان اســت. اعتبار اين

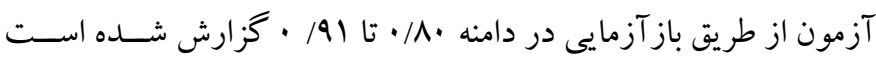
(سب- هץ). در بثزوهش حاضـر نيز ميزان اعتبار آزمون استروبِ با استفاده

$$
\text { از ضريب آلفاى كرونباخ rA/ • به دست آمد. }
$$

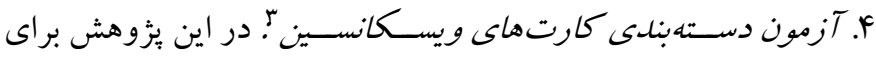
ارزيابى كار كرد توجه انتقالى از آزمون دستهبندى كارتهائ ونهاى ويسكانسين

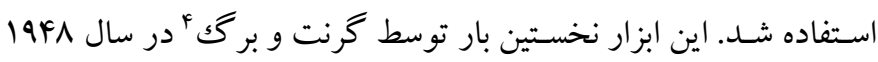

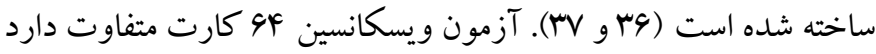

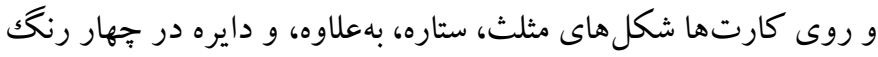

1. Stroop test

2. Ridley Stroop

3. Wisconsim Card Sorting Test 
سـازماندهى شـده اسـت كه ابعاد مختلف توجه از جمله انتخاب محر كى هـدف، انتقـال توجـه و تمركز از محركى بـه محرك ديخر به صــورت همزمـان و نكَهـدارى توجـه يـايسـار و طولـانى مـدت در كل زمان انجام تكاليف را تقويت مى كند. سـطح دشـوارى تكاليف به كونهاى بود كه با بيشــــت مهارت آزمودنى ها، تكاليف هم به طور بيش رونده دشـــوارتر

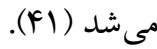

ج) معرفى برنـامه مداخلهاى: بعـد از مصــاحبه و اجر اى بيش آزمون، آزمودنى ها طبق برنامه توانبخشـى شــناختى و تقويت توجه' بيارس كه

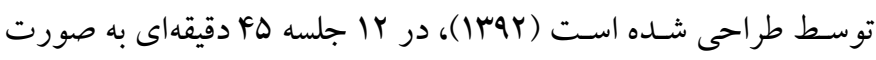
دو جلسه در هفته، تحت درمان تقويت انواع توجه قرار كرفتند. اين برنامه كه توسط ئزوهشكده علوم شناختى دانشخاه شهيد بهشتى تهر ان در سال بهوا تدوين شـده اسـت به صـورت خلاصسه در جدول ا خزارش شـده اسـت. محتو اى اين برنامه شـامل مجموعهاى از تكاليف سـلسـله مراتبى

جدول ا: برنامه توانبخشى شناختى و تقويت توجه

\begin{tabular}{|c|c|c|}
\hline اهداف و محتوا & 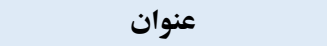 & 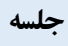 \\
\hline معرفى برنامه به دانش آموزان و ارائه دستو رالعمل ها & ايجاد رابطه و شكل دهى به درمان & يكم \\
\hline ييدا كردن حروف، اعداد، تصاوير & توجه انتخابى (مرحله 1) & \\
\hline رسم دنباله تر كيبى & توجه انتقالى (مرحله 1) & 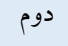 \\
\hline يبيدا كردن حروف، اعداد، تصاوير & توجه يايدار (مرحله I) & \\
\hline كاربر گكهاى كلمات رنگگى استروب & توجه انتخابى (مرحله Y) & \\
\hline نوشتن متن متوالى & توجه انتقالى (مرحله Y) & 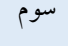 \\
\hline شمارش حروف خاص در متن (ا محركك) & توجه هايدار (مرحله Y) & \\
\hline شمارش تصوير & توجه انتخابى (مرحله r) & \\
\hline نوشتن اعداد متوالى & توجه انتقالى (مرحله r) & 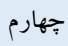 \\
\hline شمارش حروف خاص در متن (Y محرك) & توجه هِايدار (مرحله سا) & \\
\hline & 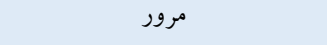 & 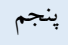 \\
\hline نوشتن بلون نقطه & توجه انتخابى (مر حله F) & \\
\hline كد گذارى (1) & توجه انتقالى (مر حله \&) & ششم \\
\hline بيدا كردن تفاوت دو تصوير & توجه پِايدار (مرحله F) & \\
\hline رسم دنباله ساده & توجه انتخابى (مرحله ه) & \\
\hline كد گذارى (r) & توجه انتقالى (مرحله ه) & 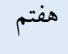 \\
\hline ييدا كردن شباهت دو تصوير & توجه پِايدار (مرحله ه) & \\
\hline ييدا كردن كلمه خاص در تصوير & توجه انتخابى (مرحله 9) & \\
\hline كد گذارى (r) & توجه انتقالى (مرحله 9) & هشتم \\
\hline ييدا كردن تصاوير (r) & توجه بِايدار (مرحله 9) & \\
\hline & 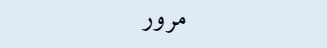 & نهم \\
\hline محاسبه اعداد سريالى ل & توجه انتخابى (مرحله V) & \\
\hline جابهجايى عدد - حرف & توجه انتقالى (مرحله V) & دهم \\
\hline انجام جدول محاسبات با قو انين حند كانه & توجه يايدار (مرحله V) & \\
\hline
\end{tabular}




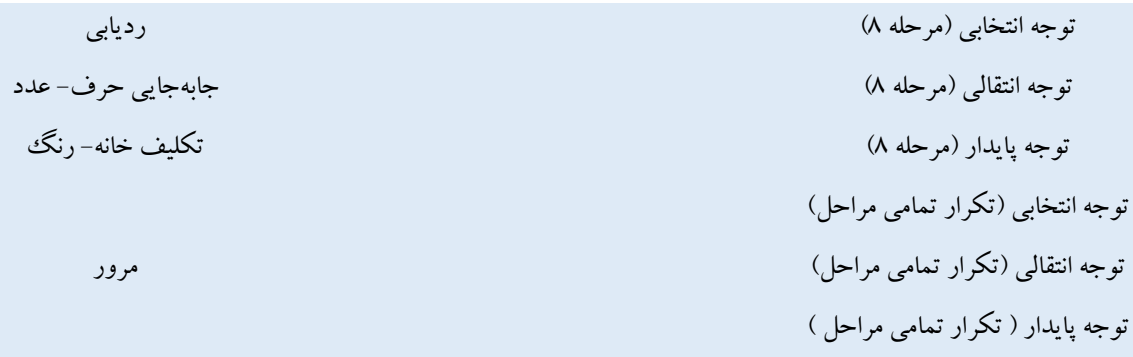

اسـميرنف و شـاييرو ويلك استفاده شد كه نتايج اين آزمونها نشان داد توزيع متغيرها نرمال اسـت (ه •/ > p). يافته هاى مربوط به تعامل زمان

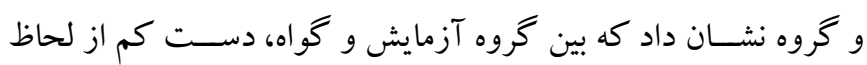
يكى از متغيرهاى وابسته، تفاوت معنادارى وجود دارد. همجينين آزمون F

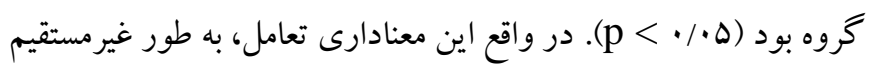

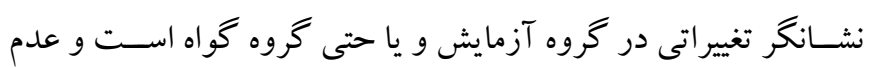

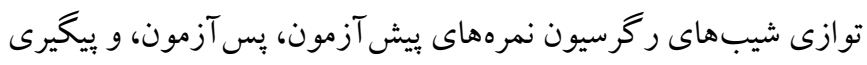

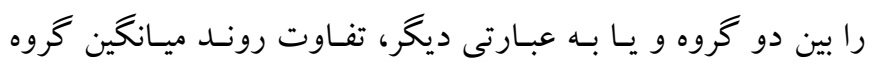

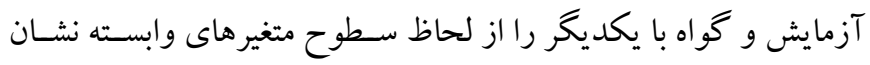

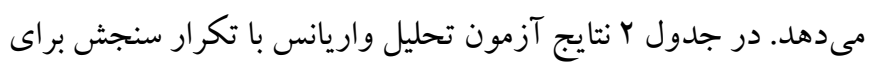

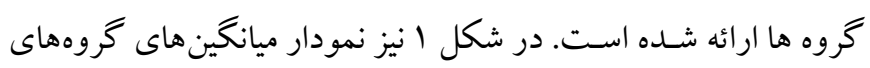

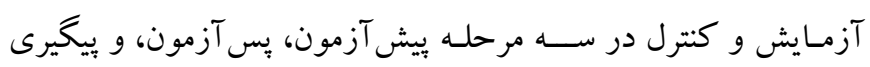
نمايش داده شده است. با توجه به جدول r و شـكل ا، در مورد مؤلفه هاى توجه انتقالى، در

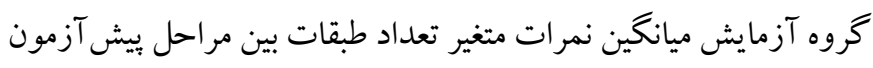

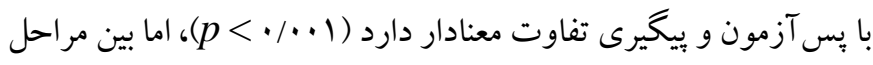

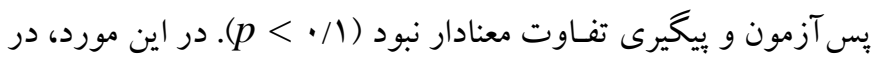
كروه گواه تفاوت نمرات بين مراحل سـه گانه اندازه خيرى، معنادار نبود.

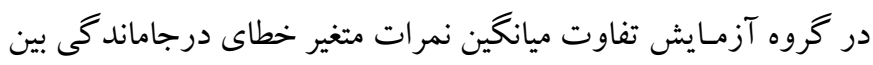

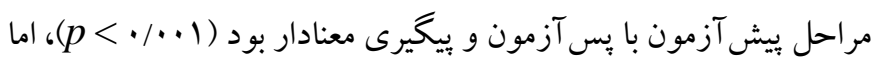

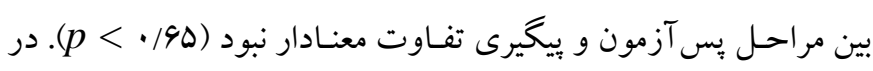

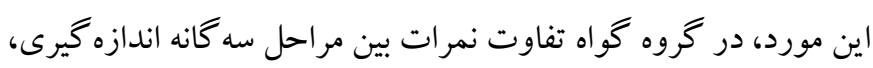

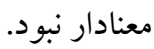

د) روش اجر ا: ابتـدا با دريافت نامه از خروه روانشــاسـى دانشـــاه

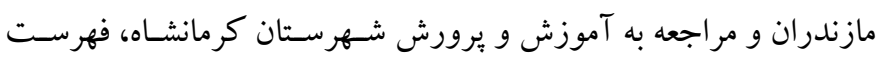

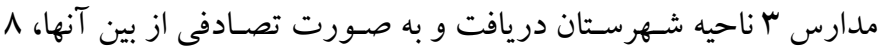

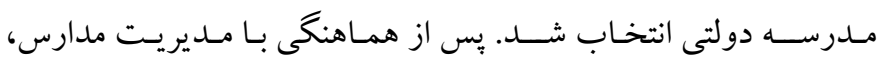

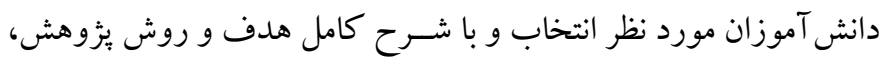

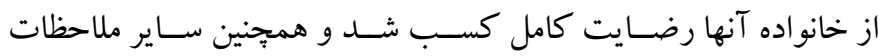

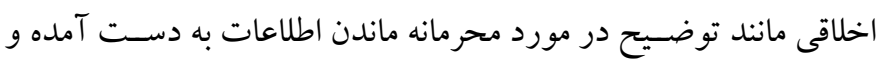

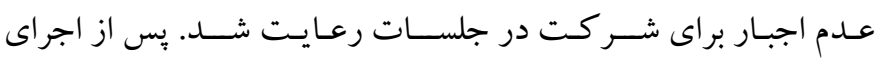

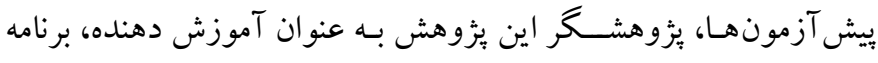

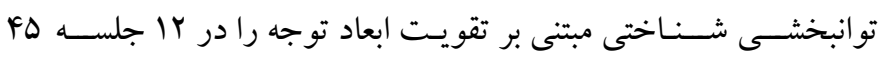

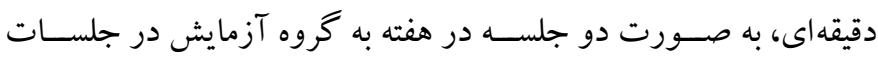

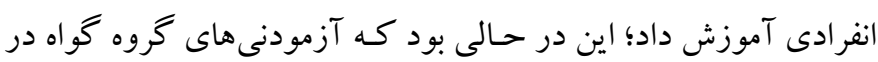
طول مدت اجراى برنامه فقط آموزش معمول كلاسى را دريافت كردند.

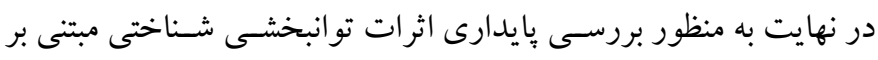

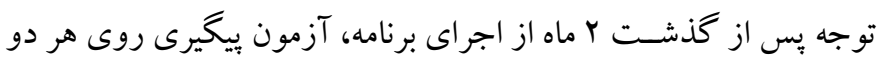

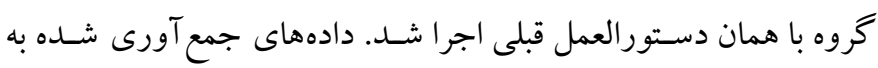

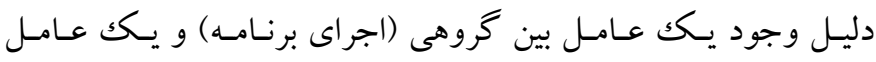

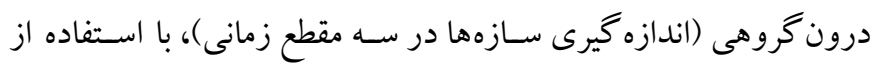
تحليـل واريـانس بـا تكرار اندازه گيرى با كمكك نرم افزار تحليل شد.

\section{يافتهها}

در اين بزوهش يكك عامل درون آزمودنى يا زمان اندازه خيرى متغيرهاى

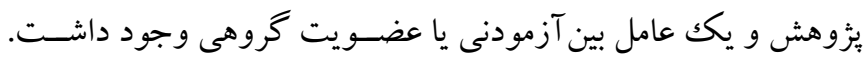

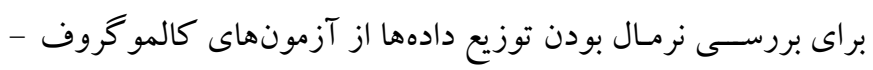


جدول r: نتايج آزمون تحليل واريانس با تكرار سنجش براى بررسى تفاوت كروه ها در متغيرهاى ثئوهش

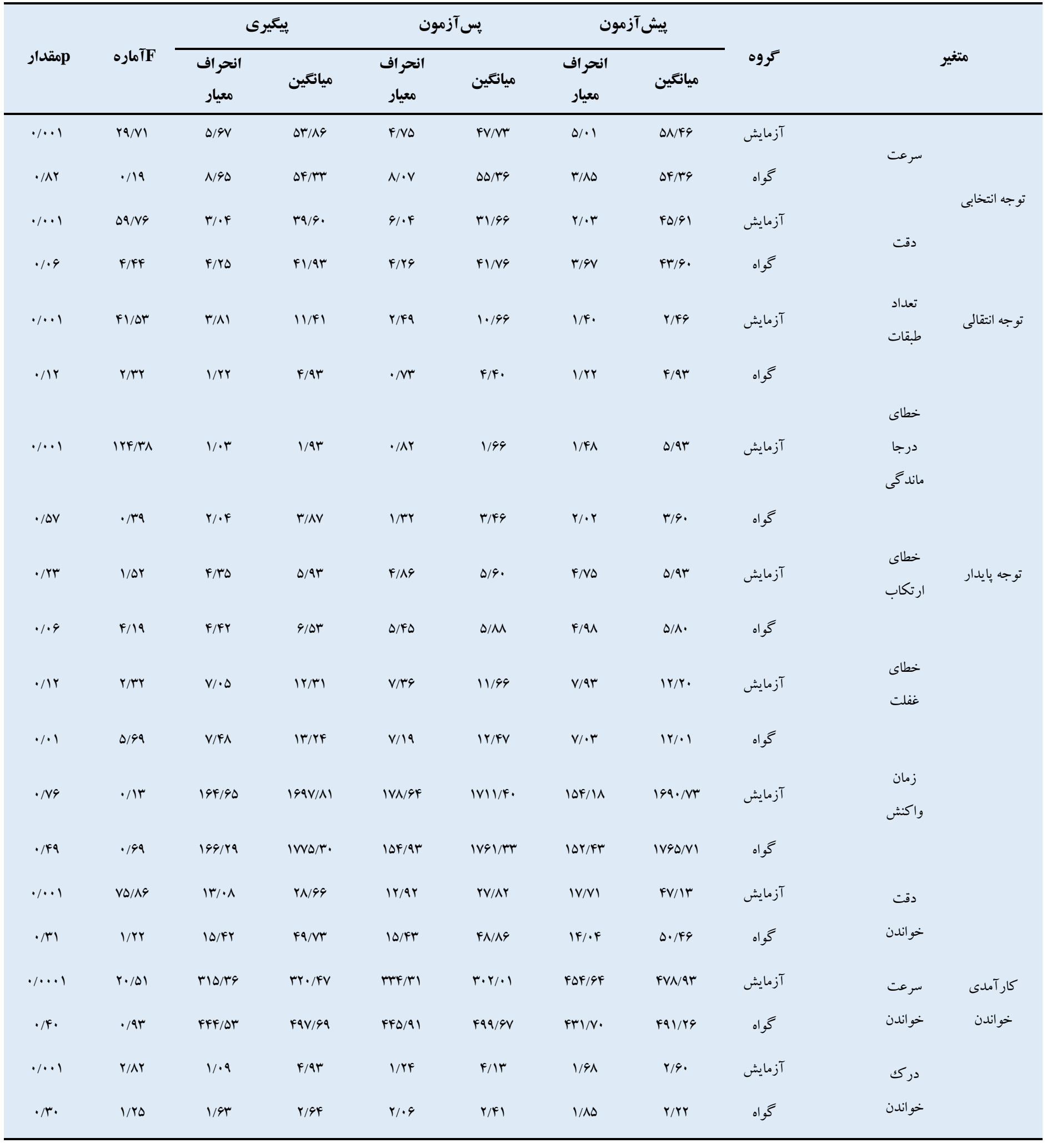




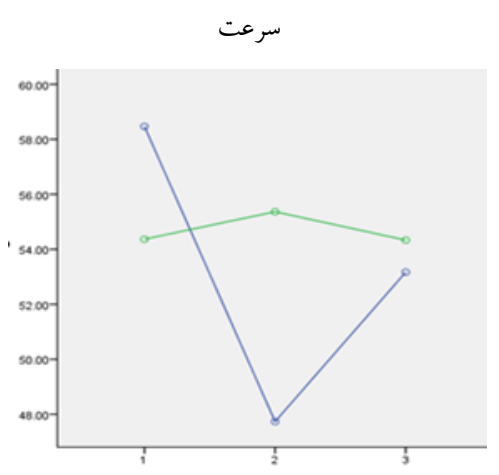

خطاى غفلت

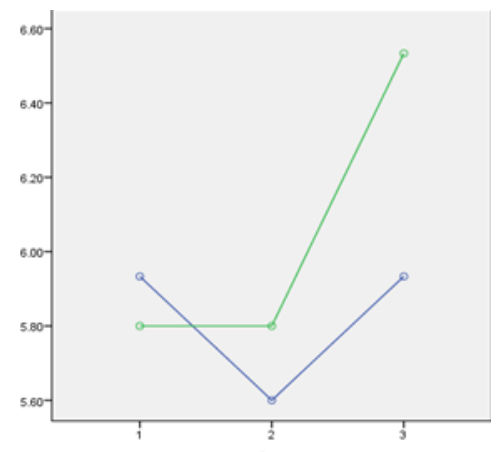

سرعت خواندن

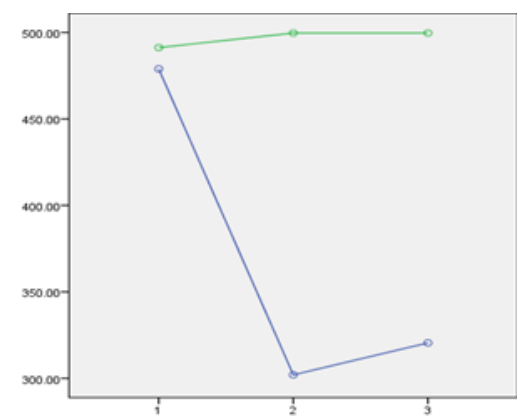

خطاى درجاماندگى

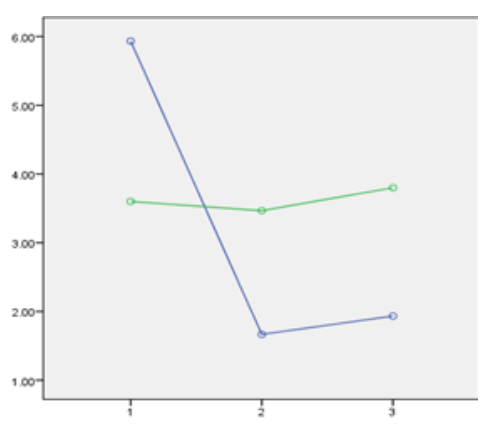

واكنش زمان

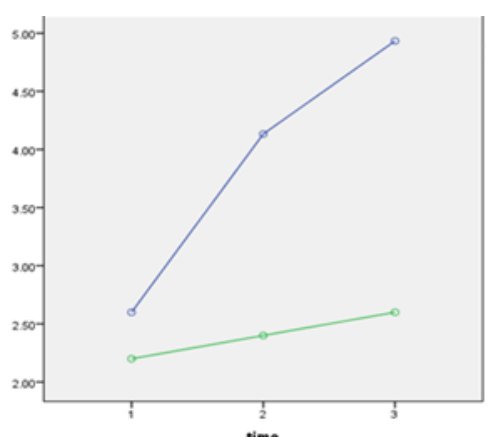

درك خو اندن
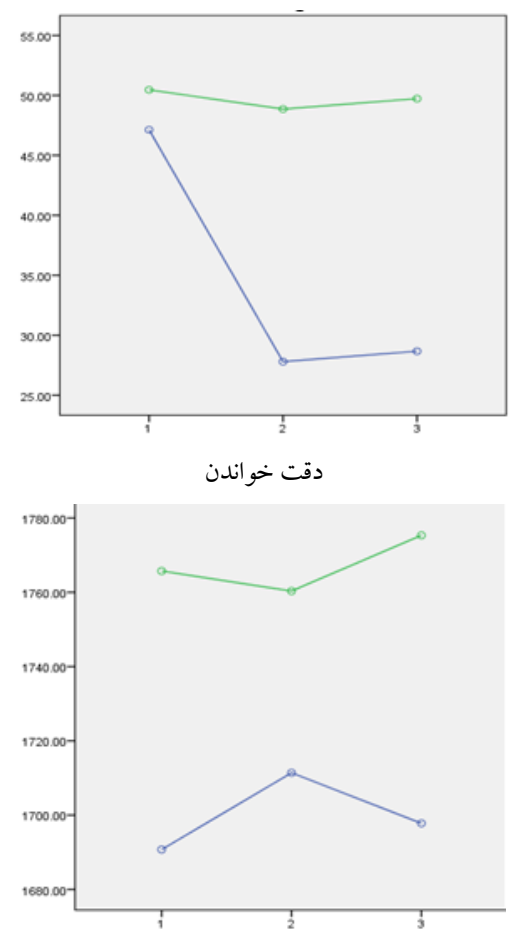

تعداد طبقات
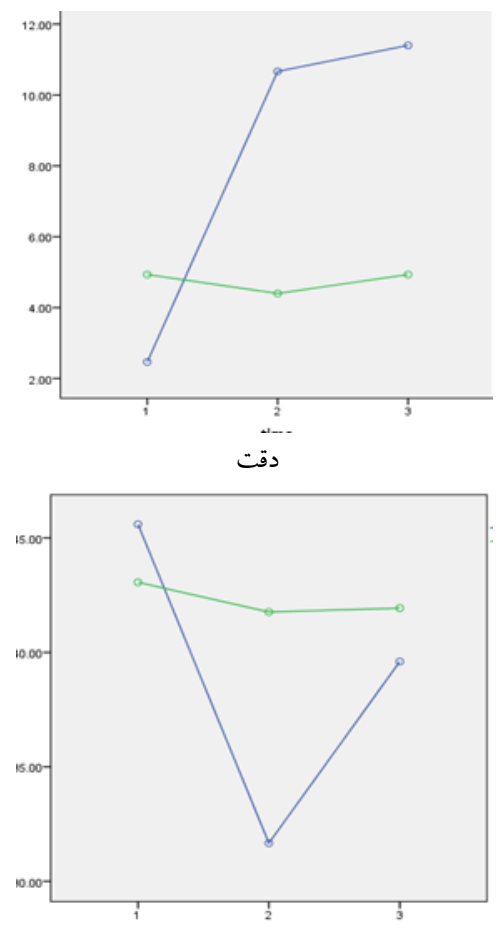

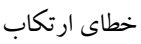

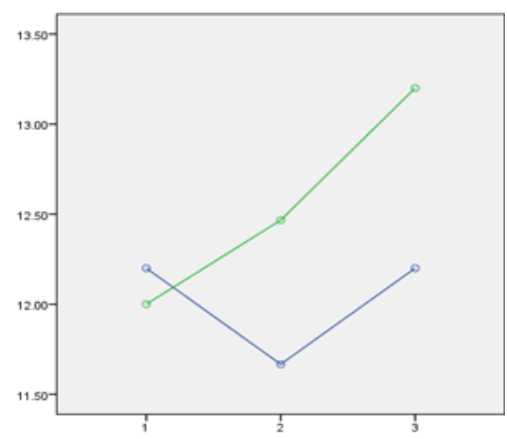

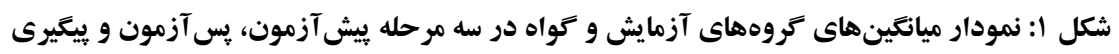

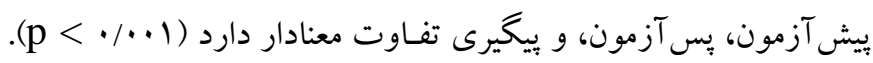

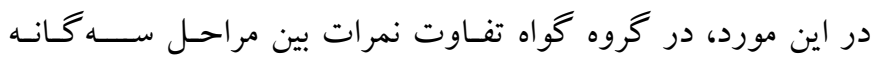

با توجه به جدول r و شكل ا، در مورد مؤلفه إى توجه انتخابى، در كروه آزمـايش ميـانخين نمرات متغيرهـاى ســرعـت و دقت بين مراحل 
نشـان دادند كه توانبخشى شناختى بر مؤلفه هاى توجه، يِيشرفت عملكرد

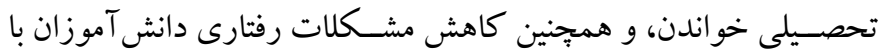

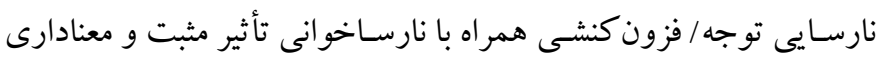

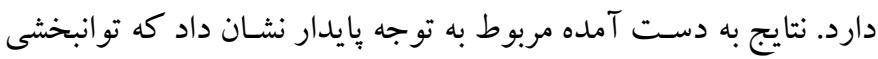

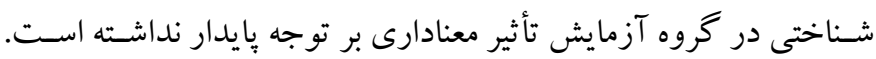

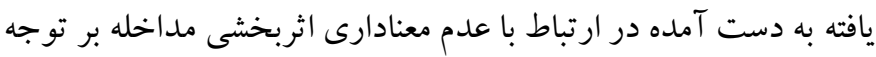
يايدار، با يافته يُوهشى كه با استفاده از برنامه آموزشى شناختى به ارتقاء توجه بايدار و حافظه فعال دست يافته بود (·r)، همسو نبود. در تبيين اين يافتهها مى توان به توانايى مغز انسـان به شـفابخشى خود لرد

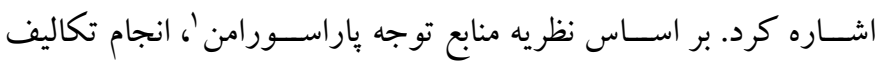
نيازمند توجه به دو دسته بزرگك تقسيم مى شوند؛ تكاليفى كه محر ككها

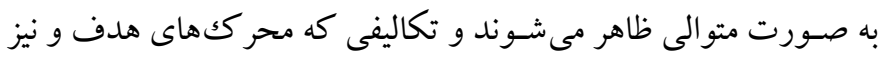

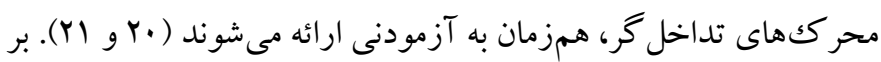

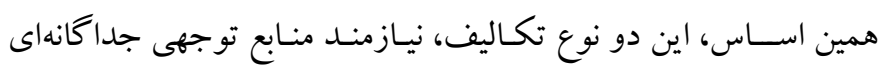

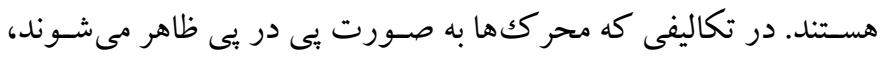

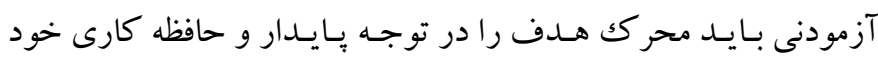
حفظ كرده و زمانى كه محر كك هدف ظاهر شــد، كليد بِاســخ را فشــار

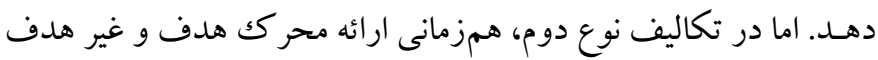

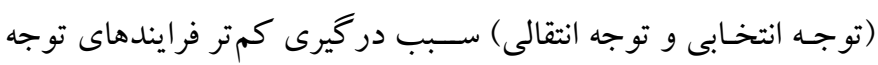
بايدار مىشود (YY). به نظر مىرسد به همين علت است است كه انجام تكاليف

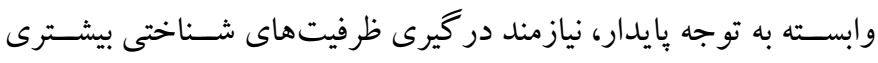

يافته يزوهش حاضر نشان داد كه دانش آموزان نارساخوان در آزمون

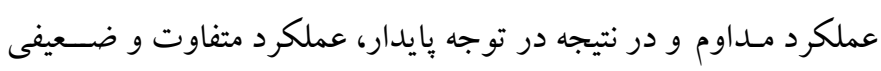

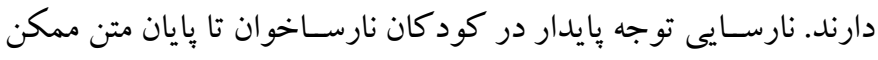
اسـت باعث شود اين كود كان خطوط نوشته شده را نيمه تمام رها كنند و

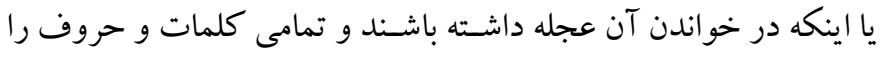

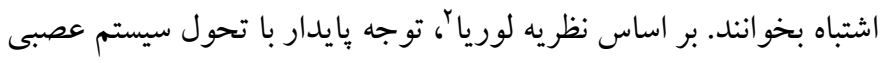
ارتباط دارد و هرجه سـن فرد افزايش يابد، مناطق قشـرى اوليه كه شـامل

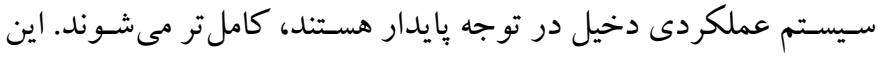
مناطق قشــى در دانش آموزان نارسـاخوان، تحول نيافته اسـت و به علت

2. Loria
انسدازهگيرى، معنـادار نبود. در مورد مؤلفههاى توجه بايدار، نه در گروه

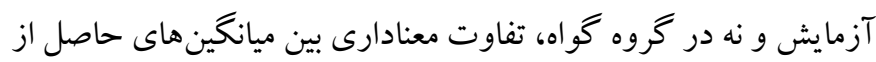

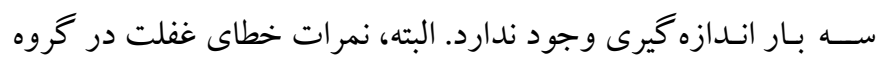

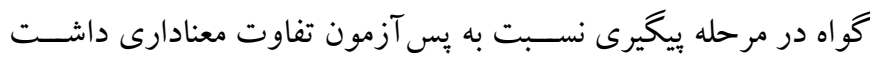
. $(\mathrm{p}<\cdot / \cdot 1)$ با توجه به جدول Y و شكل ا، در مورد مؤلفههاى كار آمدى خواندن،

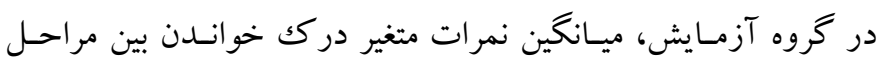

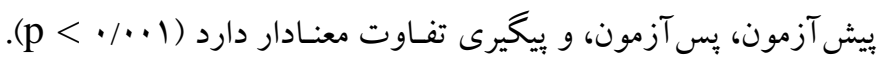

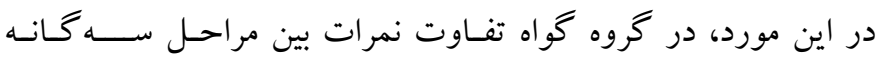

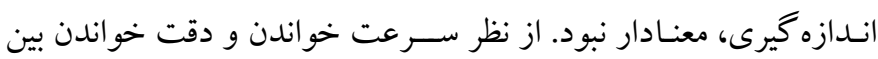

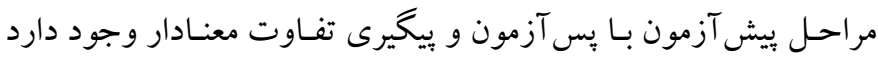

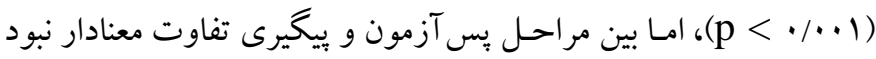

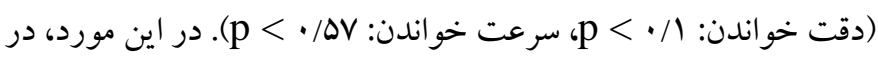
گروه گواه تفاوت نمرات بين مر احل سه كانه اندازه گيرى، معنادار نبود.

\section{بحث و نتيجه كيرى}

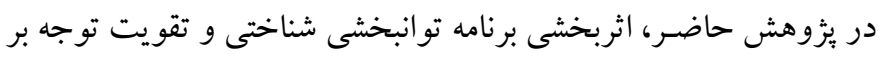

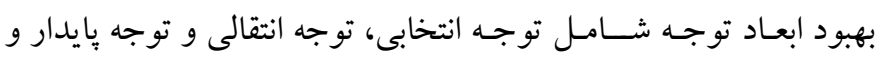

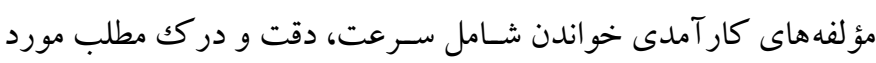

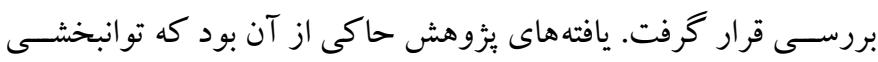

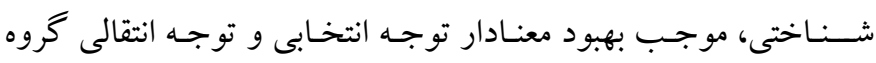

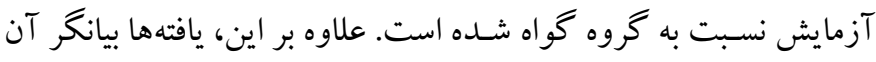

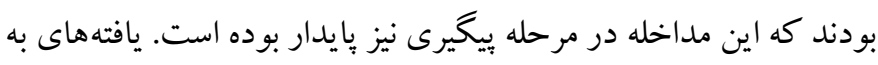

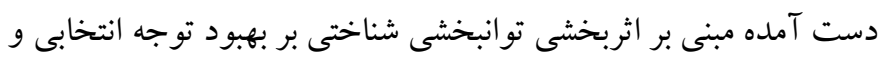

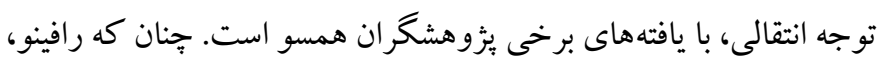

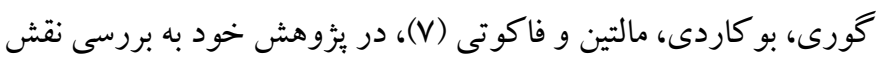

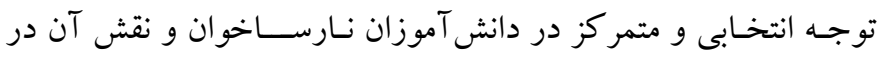

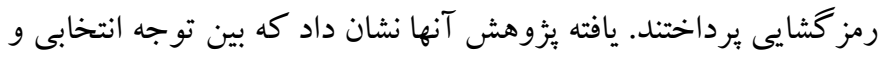

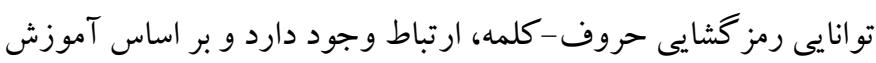

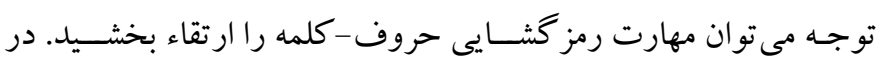

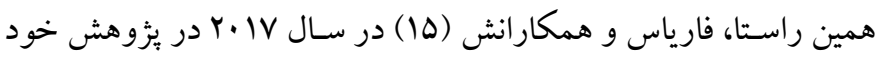

1. Parasuraman 
اين نارسايى دقت باعث افزايش خطاى درجاماندگى دانش آموز و كندى

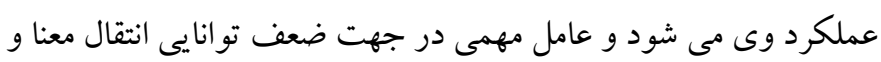

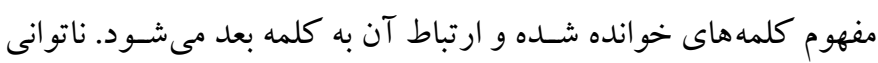

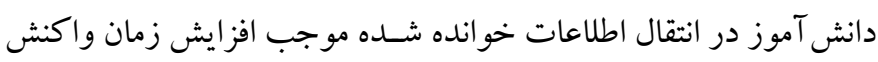

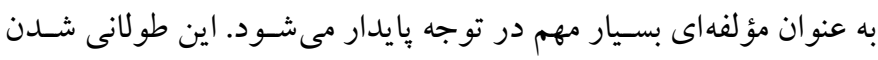

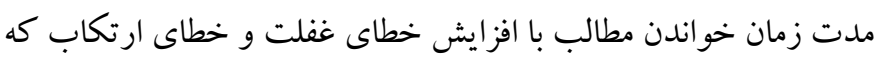
مؤلفه هاى بعدى توجه بايدار هستند، همراه مى شود (Yץ).

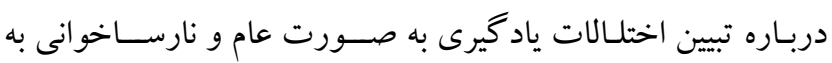

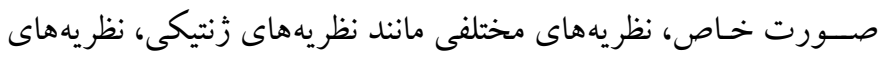
زيسـتى، نظريه هاى تحولى و رسـشـى، نظر يهاى شــناختى و نظريههاى

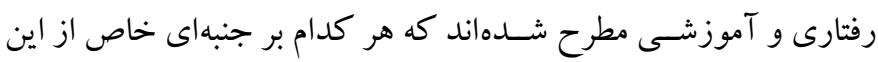

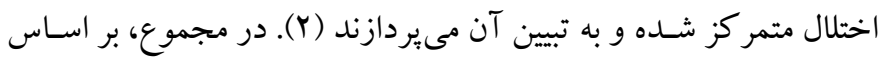

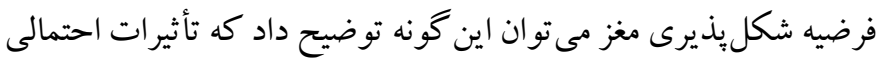

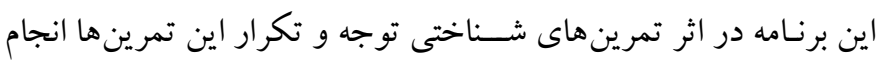

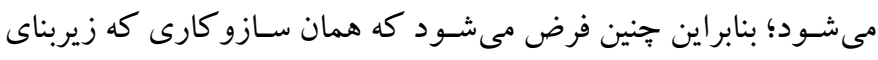

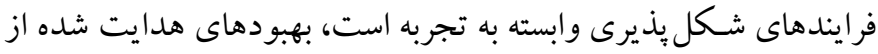
طريق توانبخشسى شـناختى را در اين اختلال به وجود آورده اسـت. نتيجه

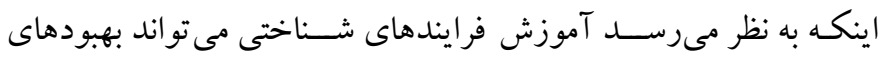

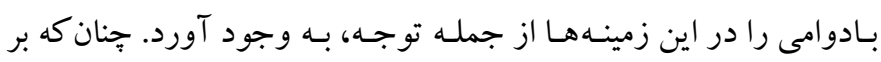
اسـاس برخى مطالعات (YY)، آموزش هاى شـناختى مكرر و هدايت شده رهاه

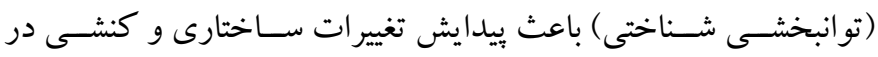

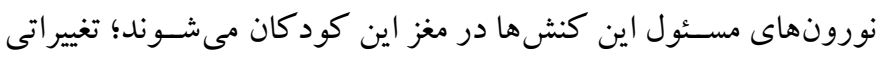

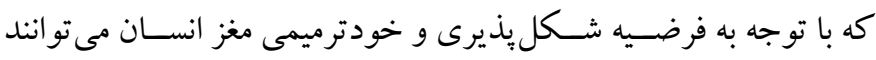

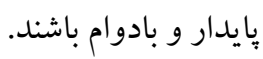

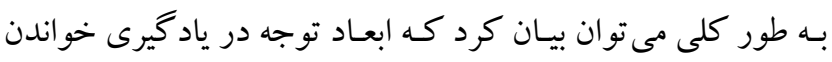

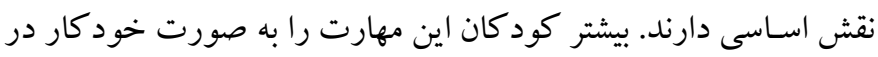

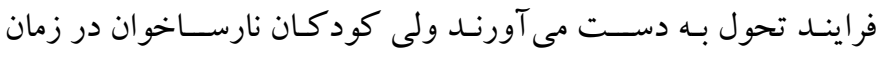

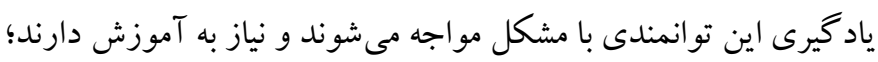

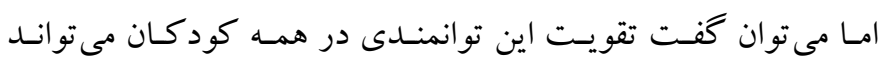

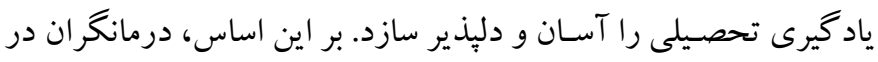

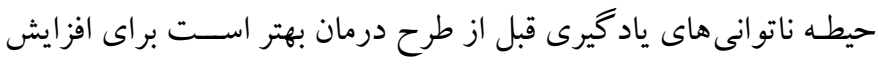

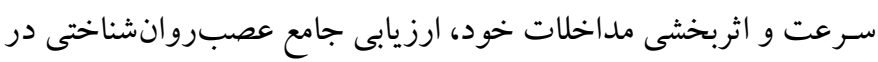

نارسـايى در عملكرد قشـر بيش ييشـانى است (YT). بيشتر مطالعات انجام شـده در حوزه توجه يايدار نشـان داده است كه اين توجه در مدت زمان لمان

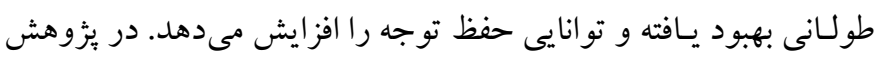

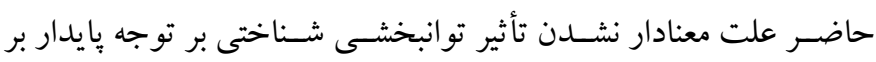

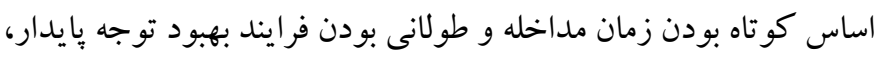
قابل توجيه است. در بايان نتايج بهدسـت آمده نشان داد كه توانبخشى شناختى توجه بر كار آمـدى خوانـدن دانش آموزان نارسـاخوان در مر احل يس بـ آزمون و

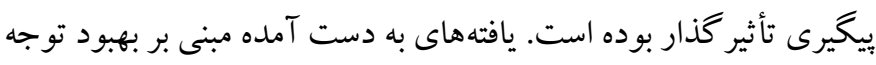

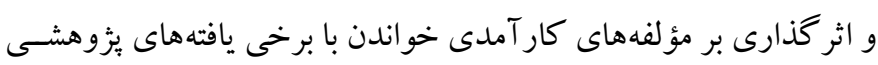

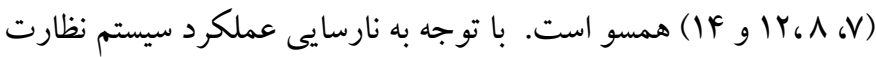

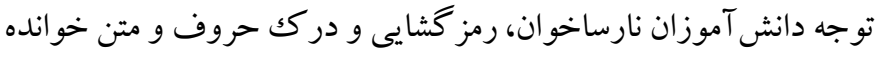

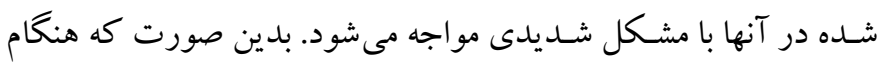
مشـاهده كلمات، قادر به تشــخص و تقسـيم آنها به هجا و واج نبوده و نمى توانند معناى واج نوشــته شــده را به طور همزمان به حروف و علائم نوشتارى انطباق دهند و در نهايت به رمز گشايى كلمه خو انده شده دست رست

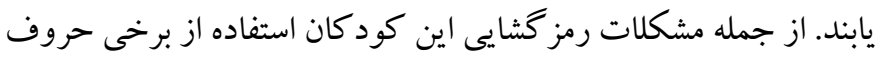

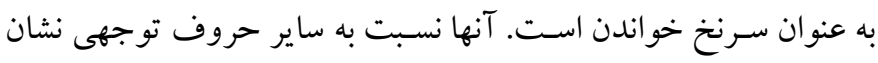

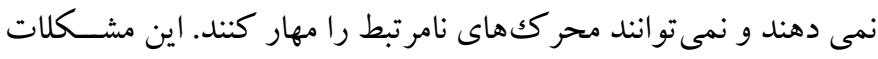

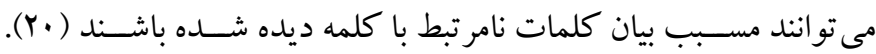
نارسايى در سيستم نظارت توجه به ناكار آمدى انعطاف يذيرى توجه منجر

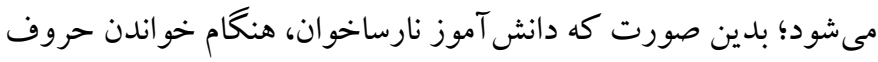

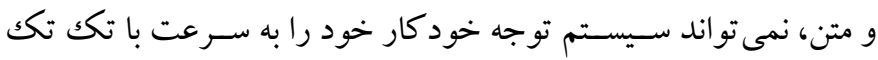

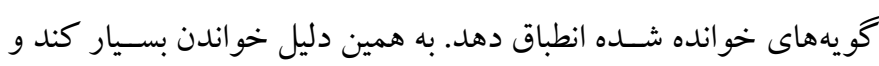

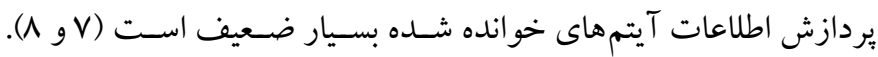

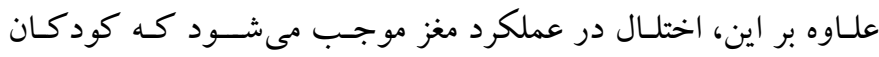

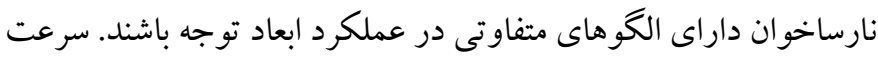

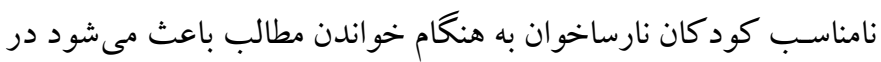

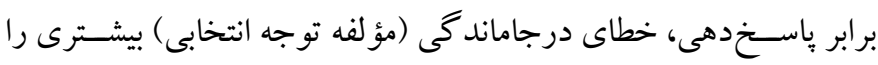

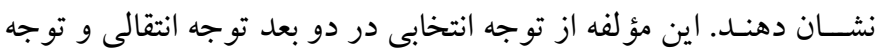

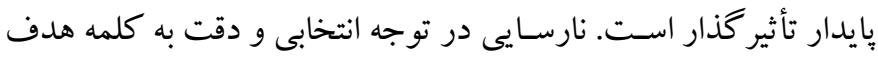
موجب سـرعت نامناسـب دانش آموزان هنگام روخو انى مطالب مى شـود. 
نيز انجام شـود و وبا سـاير برنامه هاى مطرح در اين زمينه، مقايسـه شـود.

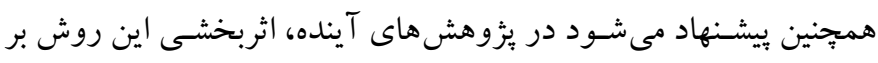

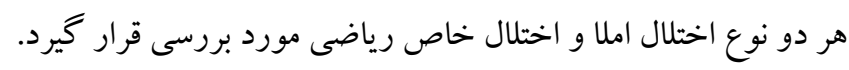

ملاحظات اخلاقى

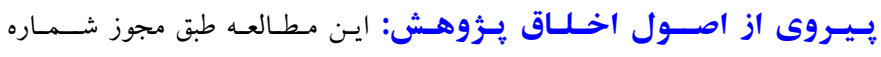

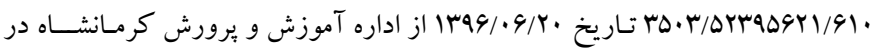

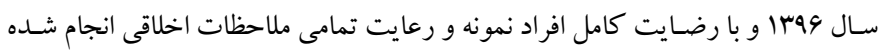

حامى مالى: اين مطالعه بدون حمايت مالى هيج كونه سـازمان و يا مؤسسه انجام شده

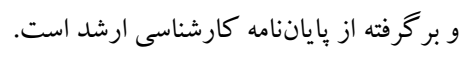

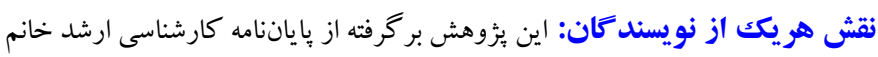

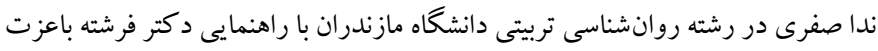

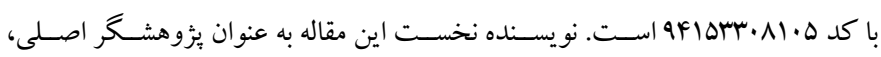

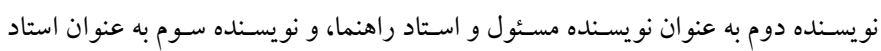
مشاور در اين مقاله نقش داشتند.

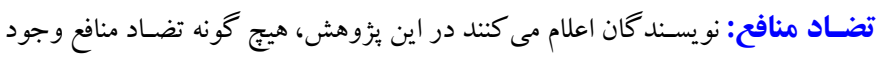
نداشته است. تشـكر و قدردانى: بد ينوسيله از مسئولان اداره آموزش و يرورش و كارشناس هسته

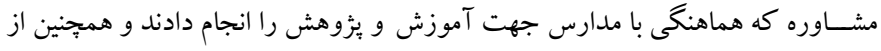

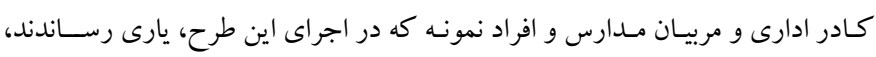

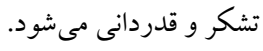

زمينه هر سه بعد توجه داشته باشند. نتايج اين بثزوهش حاكى از آن است

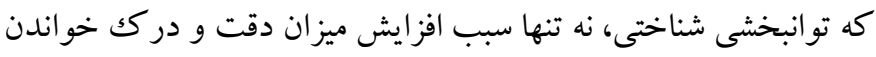

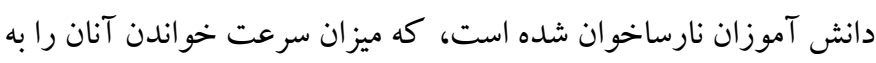

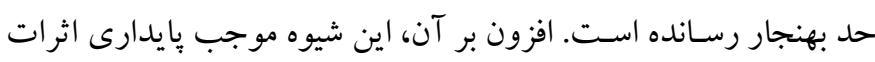

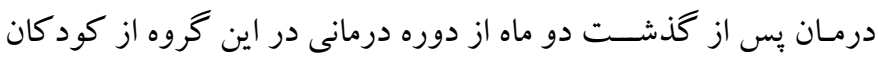

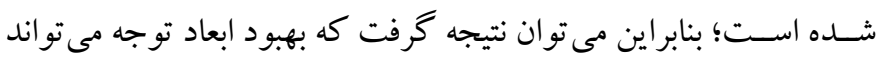

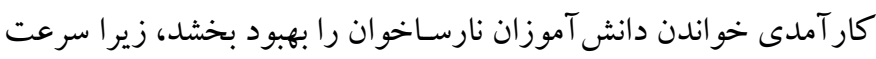

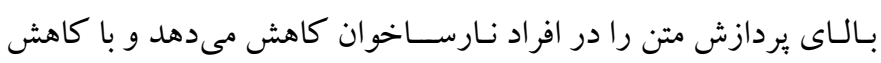

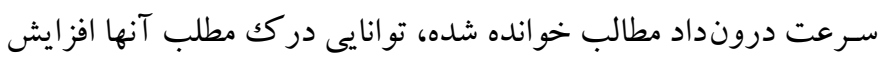
بيدا مى كند. اين بزووهش با هدف بررسى اثربخشى تو انبخشى شناختى در

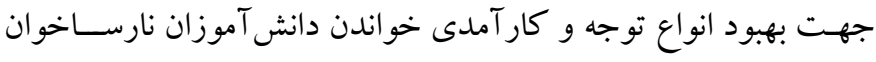

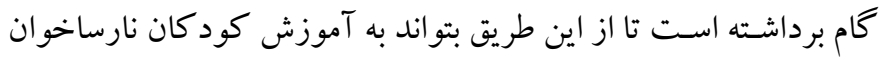

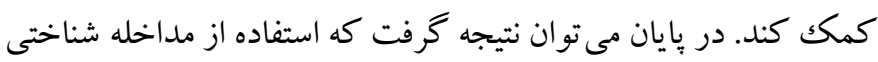

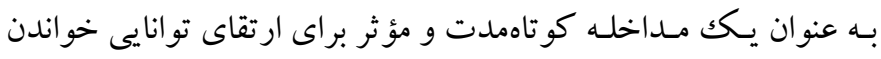

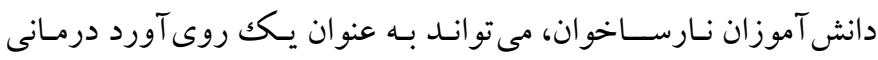

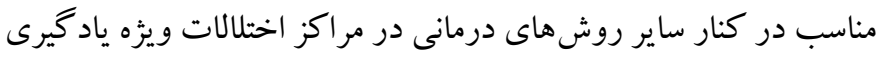

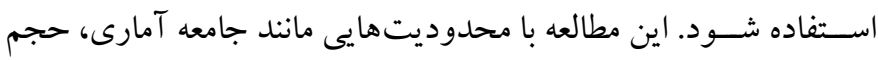

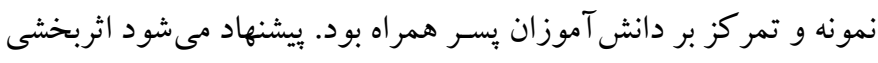

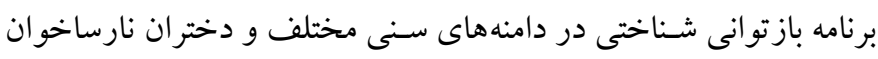




\section{References}

1. Brinkerhoff S. Learning disabilities (Living with a Special Need). New York: Mason Crest; 2015, pp: 23. [Link]

2. Petretto DR, Masala C. Dyslexia and Specific Learning Disorders: New International Diagnostic Criteria. Journal of Childhood \& Developmental Disorders. 2017; 3(4): 5-17. [Link]

3. Moshkani M, Nuori E, Lotfi M, Ebadinya G. Effect of Phonological Awareness on Improving Reading and Self-esteem of Students with Dyslexia. J Child Ment Health 2017; 4 (3): 107-118 .[Persian]. [Link]

4. Norton ES, Black JM, Stanley LM, Tanaka H, Gabrieli JD, Sawyer C, et al. Functional neuroanatomical evidence for the double-deficit hypothesis of developmental dyslexi. Neuropsychologia. 2014; 61: 235-246. [Link]

5. Maionchi-Pino N. Phonological Restriction Knowledge in Dyslexia: Universal or LanguageSpecific? Dyslexia - A Comprehensive and International Approach. 2012; 4(47): 47-60. [Link]

6. Sen S. The relationsip between the use of metacognitive strategies and reading comprehension. Procedia Social and Behavioral Sciences. 2009; 1(2): 2301-2305. [Link]

7. Ruffino M, Gori S, Boccardi D, Molteni M, Facoetti A. Spatial and temporal attention in developmental dyslexia. Frontiers in Human Neuroscience. 2014; 8(331): 1-13. [Link]

8. Fac-oetti A, Corradi N, Ruffino M, Gori S, Zorzi M. Visual spatial attention and speech segmentation are both impaired in preschoolers at familial risk for developmental dyslexia. Dyslexia. 2010; 16(3): 226239. [Link]

9. Powell T. Brain injury workbook: Exersises for cognitive rehabilitation. London: United Kingdom; 2013: 128-140. [Link]

10. Helland T, Asbjørnsen A. Executive Functions in Dyslexia. Child Neuropsychology.2000; 6(1): 37-48. [Link]

11. Moura O, Simões M, Pereira M .Executive Functioning in Children with Developmental Dyslexia. The Clinical Neuropsychologis. 2014; 28(1): 20-41. [Link]

12. Franceschini S, Gori S, Ruffino M, Pedrolli K, Facoetti A. A causal link between visual spatial attention and reading acquisition. Current Bio. 2012; 22 (3): 814-819. [Link]

13. Vidyasagar T, Pammer K. Dyslexia: A deficit in visuo- spatial attention, not in phonological processing. Trends in Cognitive Sciences. 2010; 14(2): 57-63. [Link]

14. Lewandowska M, Milner R, Ganc M, Włodarczyk E, Skarżyński, H. Attention dysfunction subtypes of developmental dyslexia. Medical Science Monitor. 2014; 20 (9): 2256-2268. [Link]

15. Farias AC, Cordeiro ML, Felden EP, Bara TS, Benko CR, Coutinho D, McCracken JT. Attention memory training yields behavioral and academic improvements in children diagnosed with attentiondeficit hyperactivity disorder comorbid with a learning disorder. Neuropsychiat Dis Treat. 2017; 13 (4): 1761-1769. [Link]

16. Gianvecchio L, French L. Sustained attention, inattention, receptive language, and story interruptions in preschool Head Start story time. J Appl Dev Psycho. 2002; 23(4): 393-407. [Link]

17. Lima RF, Azoni CA, Ciasca SM. Attentional and executive deficits in Brazilian children with developmental dyslexia. Psychology. 2013; 4(10): 16. [Link]

18. Kamran A, Moghtadaie K, Abdali Z, Salamat M. The Effectiveness of Attention Training on Improving the Academic Performance of Students with Spelling Learning Disabilities. J Child Ment Health. 2017; 4 (1): 46-55. [Persian]. [Link]

19. Sternberg RJ, Sternberg K. Cognitive psychology. Sixth Edition. Wadsworth: Cengage Learning; 2015: 135-252. [Link]

20. Avtzon S. Effect of neuroscience based cognitive skill training on growth of cognitive deficits associated with learning disabilities in children grades 2-4. Journal of Learning Disabilities. 2012; 18(3): 111-22. [Link].

21. Parasuraman R. Memory load and event rate control sensitivity decrements in sustained attention. Science. 1979; 205(4409): 924-927. [Link]

22. Varvara P, Varuzza C, Sorrentino A, Vicari S, Menghini D. Executive functions in developmental dyslexia. Frontiers in Human Neuroscience. 2014; 8(120): 1-13. [Link]

23. Yuri, Mikadze, Alfredo, Tatiana, V. A.R. Luria's approach to neuropsychological assessment and rehabilitation. Archives of Clinical Neuropsychology. 2018; 1: 1-8. [Link]

24. Altemeier LE, Abbott RD, Berninger VW. Executive functions for reading and writing in typical literacy development and dyslexia. J. Clin. Exp. Neuropsychol. 2008; 30(5): 588-606. [Link] 
25. Reck SG, Hund AM. Sustained attention and age predict inhibitory control during early childhood. J Exp Child Psycho. 2011; 108(3): 504-512. [Link]

26. Nejati v. Comprehensive textbook of cognitive rehabilitation in developmental disorders. Tehran, Roshdefarhang; (2018), pp: 411-440. [Persian]. [Link]

27. Fathi astiani $\mathrm{M}$, akhavan tafti $\mathrm{M}$, khademi $\mathrm{M}$. The Effectiveness of cognitive training on information processibg speed and working memory in children with learning disabilities.2017; 12(41): 125-141. [Persian]. [Link]

28. Dehghani Y, Afshin S A, Keykhosrovani M. Effectiveness of Neuropsychological Therapy on Executive Functions and Educational Performance of Students with Dyscalculia. J Child Ment Health. 2017; 3 (4):14-25. [Persian]. [Link]

29. Rahmani A, Pirani Z, Heidari H, Davoodi H. The effectiveness of cognitive rehabilitation training on work memory and selective attention of dyslexic students in elementary schools. Journal of Learning Disabilities. 2019; 8 (2): 167-174. [Persian]. [Link]

30. Sadeghi A, Rabiee M, Abedi M. Validation and reliability of the Wechsler Intelligence Scale for Children-IV. Developmental Psychology: Journal of Iranian Psychologists. 2011; 7(28): 377-386. [Persian]. [Link]

31. Abedi MR, Sadeghi A, Rabiei M. Standardization of the Wechsler Intelligence Scale for Children- IV in Chahar Mahal Va Bakhteyri State. Journal of Personality \& Individual Differences. 2013; 2(3): 138-158. [Persian]. [Link]

32. Baezzat F. The effects of neuropsychological intervention (HAS) on reading and writing efficiency of linguistically dyslexic students: Single case study. Journal of Applied Psychology .2009; 3(3): 7-19. [Persian]. [Link]

33. Macleod CM. Half a century of research on the Stroop effect: An integrative review. Psycho Bull. 1991; 109 (2): 163-203. [Link]
34. Lezak MD, Howieson DB, Loring DW, Hannay HJ. Neuropsychological Assessment. 4th edition. New York, US, NY: Oxford University Press. 2004, pp: 202-205. [Link]

35. Mashhadi A, Rasoulzadeh-Tabatabaie K, Azadfallah P, Soltanifar A. The Comparison of Response Inhibition and Interference Control in ADHD and Normal Children. Psychology Clinical of Journal. 2009; 1(2): 37-50. [Link]

36. Craig AB, Phillips ME, Zaldivar A, Bhattacharyya R, Krichmar JL. Investigation of biases and compensatory strategies using a probabilistic variant of the Wisconsin Card Sorting Test. Front Psychol. 2016; 7: 678-691. [Link]

37. Bahrami H, Nejati V, Pooretemad H. A comparative study of phonemic and semantic verbal fluency in children and adolescents with developmental stuttering and normal peers Zahedan. J Res Med Sci. 2014; 16(5): 4-41. [Persian]. [Link]

38. Aliloo MM, Hamidi S, Shirvani A. Comparison of executive function and sustained attention in students with obsessivecompulsive, high schizotypal and overlapping symptoms with the normal group. J Res Behav Sci. 2011; 9(3): 216-21. [Persian]. [Link]

39. Shahgholian M, Azad Fallah P, Fat'hi Ashtiani A, Khodadadi M. Wisconsin card sorting test software: Theory, construction and psychometric properties. Clinical Psychology Studies. 2012; 1 (4): 111-133. [Persian]. [Link]

40. Hadianfard H, Najjarian B, Shokrkon H, Mehrabizadeh Honarmand M. Preparatin and production of Persian version of Continuous Performance Test. Psychology. 2000; 4 (4): 388-440 [Persian]. [Link]

41. Ramezan Nia Z, Nejati V. Effectiveness of PARS cognitive rehabilitation program on the improvement of executive function in children with ADHD. Scientific Journal of Rehabilitation Medicine. 2017; 6 (4): 219-230. [Persian]. [Link] 